\title{
Catalysts from synthetic genetic polymers
}

\author{
Alexander I. Taylor ${ }^{1}$, Vitor B. Pinheiro ${ }^{1} \dagger$, Matthew J. Smola ${ }^{2}$, Alexey S. Morgunov ${ }^{1}$, Sew Peak-Chew ${ }^{1}$, Christopher Cozens ${ }^{1}$, \\ Kevin M. Weeks ${ }^{2}$, Piet Herdewijn ${ }^{3,4}$ \& Philipp Holliger ${ }^{1}$
}

\begin{abstract}
The emergence of catalysis in early genetic polymers such as RNA is considered a key transition in the origin of life ${ }^{1}$, pre-dating the appearance of protein enzymes. DNA also demonstrates the capacity to fold into three-dimensional structures and form catalysts in vitro ${ }^{2}$. However, to what degree these natural biopolymers comprise functionally privileged chemical scaffolds ${ }^{3}$ for folding or the evolution of catalysis is not known. The ability of synthetic genetic polymers (XNAs) with alternative backbone chemistries not found in nature to fold into defined structures and bind ligands ${ }^{4}$ raises the possibility that these too might be capable of forming catalysts (XNAzymes). Here we report the discovery of such XNAzymes, elaborated in four different chemistries (arabino nucleic acids, $\mathrm{ANA}^{5} ; \mathbf{2}^{\prime}$-fluoroarabino nucleic acids, FANA ${ }^{6}$; hexitol nucleic acids, HNA; and cyclohexene nucleic acids, $\mathrm{CeNA}^{7}$ ) directly from random XNA oligomer pools, exhibiting in trans RNA endonuclease and ligase activities. We also describe an XNA-XNA ligase metalloenzyme in the FANA framework, establishing catalysis in an entirely synthetic system and enabling the synthesis of FANA oligomers and an active RNA endonuclease FANAzyme from its constituent parts. These results extend catalysis beyond biopolymers and establish technologies for the discovery of catalysts in a wide range of polymer scaffolds not found in nature ${ }^{8}$. Evolution of catalysis independent of any natural polymer has implications for the definition of chemical boundary conditions for the emergence of life on Earth and elsewhere in the Universe?.
\end{abstract}

Life is dependent on catalysis, as many chemical transformations essential for cellular function are kinetically sluggish and/or thermodynamically disfavoured under ambient conditions. The emergence of a catalyst (or catalytic system) for RNA self-replication is considered to have been a key event in the origin of life. Thus the development of molecular heredity itself depends not only on the capacity of nucleic acids for genetic information storage and retrieval but also on their ability to form catalysts ${ }^{1}$. Although proteins have largely supplanted this role in present-day biology, nucleicacid-mediated catalysis remains crucial, notably in RNA processing ${ }^{10}$ and translation $^{11}$. Furthermore, a range of RNA and DNA enzymes (ribozymes/DNAzymes) have been discovered by in vitro evolution ${ }^{12}$.

Catalysis by nucleic acids (and by biopolymers in general) requires as a minimum the presence of chemically functional groups and a framework for their precise arrangement. Synthetic genetic polymers (XNAs) with backbones based on congeners of the canonical ribofuranose share with RNA and DNA a capacity for heredity, evolution and the ability to fold into defined three-dimensional structures, forming ligands (aptamers) ${ }^{4}$. We therefore sought to establish whether XNAs could also support the evolution of catalysts.

Taking advantage of XNA replication technology developed previously ${ }^{4}$, we devised a strategy for the discovery of RNA endonuclease XNAzymes by cleavage of an internal RNA sequence (Extended Data Fig. 1). Chimeric RNA-XNA libraries were prepared by RNA-primed XNA synthesis in four scaffolds using mutant polymerases: $\mathrm{D} 4 \mathrm{~K}^{4}$ for arabinonucleic acid $(\mathrm{ANA})^{5}$ and fluoro-arabinonucleic acid (FANA) ${ }^{13}, 6 \mathrm{G} 12^{4}$ for cyclohexenyl nucleic acid (CeNA $)^{7}$ and a newly engineered 6G12 I521L variant (see Methods) for 1,5 anhydrohexitol nucleic acid (HNA) ${ }^{7}$. After 13-17 rounds of selection, polyclonal pools showed RNA endonuclease activity and were deep sequenced (Extended Data Fig. 2). Abundant sequences across all four XNAs were tested for intramolecular (in cis) endonuclease activity and a subset of active clones for bimolecular (in trans) activity. We further examined one RNA endonuclease XNAzyme for each scaffold (FR17_6 (FANA), AR17_5 (ANA), HR16_1 (HNA) and CeR16_3 (CeNA)) (Fig. 1). All showed site-specific sequence-dependent (Extended Data Fig. 3) RNA cleavage with a range of catalytic rates $\left(k_{\mathrm{obs}}=\right.$ $0.06-0.0001 \mathrm{~min}^{-1}$ at $25^{\circ} \mathrm{C}$ ). While the rate of the FR17_6 XNAzyme is comparable to analogous ribozymes and DNAzymes, ANA and in particular HNA and CeNA catalysts are 20-600-fold slower. Nevertheless, all four catalyse RNA cleavage through a classic transesterification mechanism (as seen in, for example, the 'hammerhead' or 'hairpin' ribozymes ${ }^{14}$ ), yielding products with $2^{\prime}, 3^{\prime}$ cyclic phosphate and $5^{\prime}$ hydroxyl groups (Extended Data Fig. 4).

We dissected contributions of individual nucleotides in the FR17_6 XNAzyme, defining a 26 nucleotide (nt) catalytic core (FR17_6min). As all four FANA nucleotide phosphoramidites are commercially available, this minimized XNAzyme could be prepared by solid-phase synthesis (see Methods) and was found to retain near full activity (Fig. $2 \mathrm{a}-\mathrm{c} ; k_{\mathrm{obs}}=$ $0.026 \mathrm{~min}^{-1}$ at $25^{\circ} \mathrm{C}$ ), including multiple turnover catalysis (Fig. 2d). FR17_6min shows a pH optimum ( $\mathrm{pH}_{\text {opt }}$ ) of 9.25 (Extended Data Fig. 4h), consistent with a mechanism involving deprotonation of the cleavage siteproximal 2 ' hydroxyl. A screen of Irving-Williams divalent metals reveals that FR17_6min is $\mathrm{Mg}^{2+}$-dependent with an apparent Michaelis constant $K_{\mathrm{m}} \approx 30 \mathrm{mM}$ (Extended Data Fig. 4i), with only $\mathrm{Mn}^{2+}$ able to partially restore activity (Extended Data Fig. 4g).

The secondary structure of FR17_6, including an inert RNA substrate modified with $2^{\prime} \mathrm{O}-\mathrm{Me}$ at the cleavage site (Extended Data Fig. 5), was probed by selective $2^{\prime}$ hydroxyl acylation analysed by primer extension (SHAPE) ${ }^{15}$ (for RNA, modifying $2^{\prime} \mathrm{OH}$ at flexible regions) and/ or dimethyl sulphate (DMS) ${ }^{16}$ (for FANA, modifying primarily unpaired adenine and cytosine). This secondary structure is broadly similar to other RNA-acting nucleic acid catalysts, with a central domain flanked by substrate-binding arms (P1, P2), albeit with a 3 nt bulge in P2 (Extended Data Fig. 5c).

In general, the RNA endonuclease XNAzymes are novel sequences, although some in the ANA system (Extended Data Fig. 2c) retain partial sequences from the 8-17 and 10-23 DNAzymes ${ }^{17}$ used in library design (in addition to $\mathrm{N}_{40}$ sequences)(see Methods). The AR17_5 ANAzyme shares 12 of the 14 core residues of the 8-17 DNAzyme, as well as $A^{\prime} G>N^{\prime} G$ cleavage preference (Extended Data Fig. 3b). However, conversion of the complete 8-17 sequence into ANA (or indeed FANA, HNA or CeNA) yields no activity (Extended Data Fig. 3e), indicating the acquisition or rearrangement of key residues during selection. Nevertheless, topological similarities (without sequence homology) between FR17_6 and this family of DNAzymes ${ }^{18}$ suggests the possibility that for XNAs that form DNA-like B-form duplexes, such as ANA and FANA (albeit with a non-canonical O $4{ }^{\prime}$-endo (east) sugar conformation $)^{19}$, catalysts may reside in the structural or sequence vicinity of extant DNAzymes. 
a
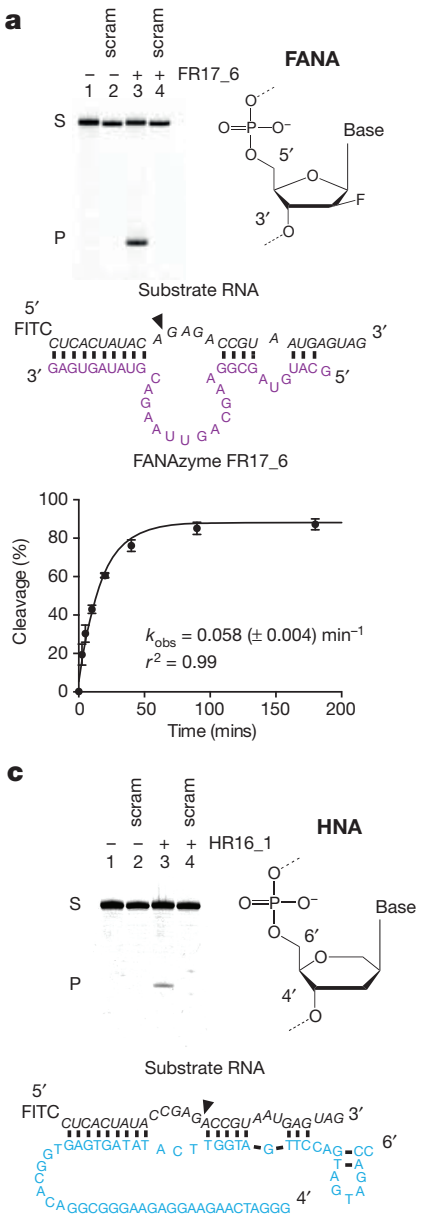

HNAzyme HR16 1

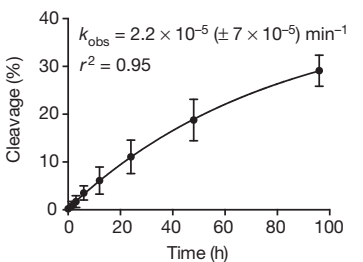

b
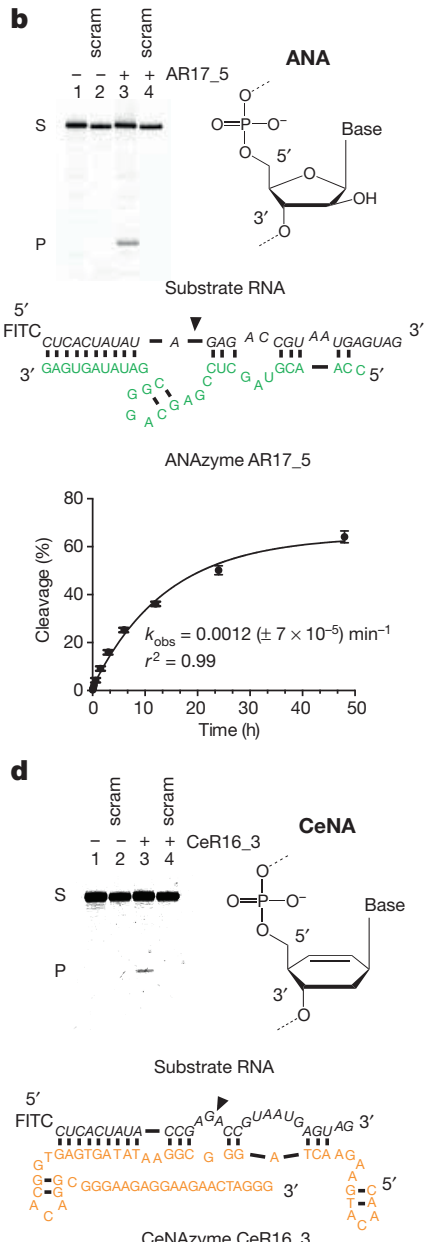

CeNAzyme CeR16_3

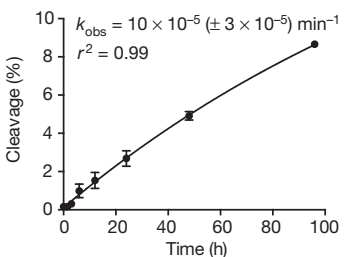

Figure $1 \mid$ RNA endonuclease XNAzymes elaborated in four synthetic genetic polymer chemistries. Shown are gel electrophoretograms, putative secondary structures, and pre-steady state reaction rates $\left(k_{\text {obs }}\right)$ at $25^{\circ} \mathrm{C}(n=3$; error bars, s.d.) of enzymes composed of XNA: FANA (a), ANA (b), HNA (c) and CeNA (d). Urea-PAGE gels show bimolecular cleavage (in trans) of cognate RNA substrates $\left(\mathrm{NucS}^{\mathrm{R}}\right.$ variants, see Extended Data Fig. 3) (lanes 1 and 3 ), but not scrambled RNA (NucS ${ }^{\text {RCRAM1 }}$ ) (lanes 2 and 4), catalysed by XNAzymes (lanes 3 and 4). Bands representing substrates and products are marked $\mathrm{S}$ and $\mathrm{P}$, respectively.

Having established the capacity for catalysis in four different XNA backbones, we wondered whether XNAzymes could be evolved to ligate RNA as well as cleave it ${ }^{20-22}$. We selected for RNA-RNA ligase activity using a bi-molecular strategy: $5^{\prime}$-RNA-XNA libraries carrying $5^{\prime}$ triphosphate moieties (5' ppp)(Extended Data Fig. 6) were challenged to ligate to DNA-RNA-3' substrates. We identified RNA ligase XNAzymes (FANA) by deep sequencing and screening (Extended Data Fig. 7), and chose one (F2R17_1) for further characterization. A minimized (39 nt), chemically synthesized version (F2R17_1min) was capable of ligating two RNA substrates $\left(\mathrm{LigS1}^{\mathrm{R}}\left(3^{\prime} \mathrm{OH}\right)+\operatorname{LigS2}^{\mathrm{R}}\left(5^{\prime} \mathrm{ppp}\right)\right)$ in a tri-molecular reaction (Fig. 3) with 'natural' regioselectivity $\left(3^{\prime}-5^{\prime}\right.$ rather than $\left.2^{\prime}-5^{\prime}\right)$, as judged by comparison with 'mock' RNA using strong anion exchange chromatography (SAX-HPLC)(Extended Data Fig. 7c). The reaction rate is low $\left(k_{\mathrm{obs}}=\right.$ $2 \times 10^{-4} \min ^{-1}$ at $\left.25^{\circ} \mathrm{C}\right)$, but represents an enhancement $\left(k_{\text {obs }} / k_{\text {uncat }}\right)$ of
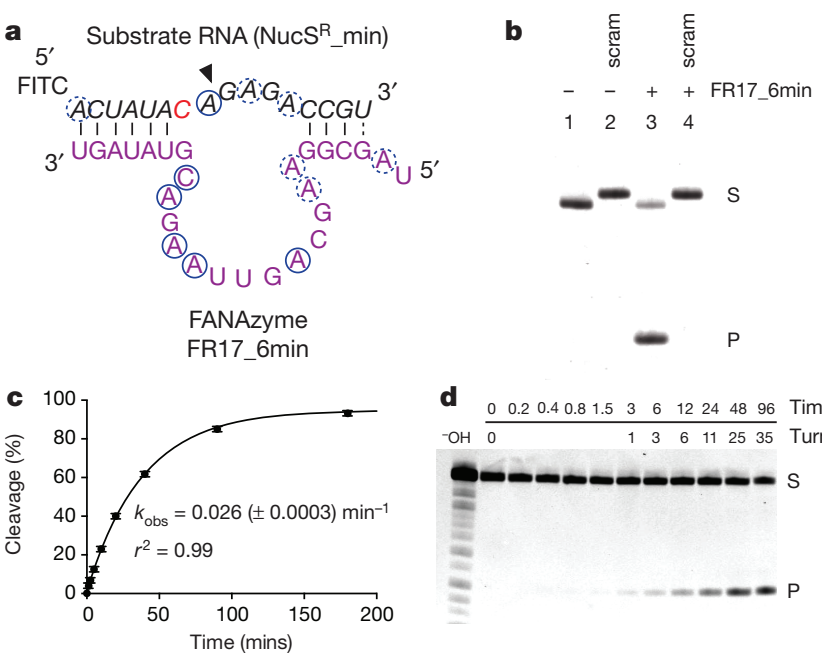

d \begin{tabular}{llllllllllll}
0 & 0.2 & 0.4 & 0.8 & 1.5 & 3 & 6 & 12 & 24 & 48 & 96 & Time (h) \\
\hline
\end{tabular} $\begin{array}{llllllll} & \mathrm{OH} & 1 & 3 & 6 & 11 & 25 & 35\end{array}$ Turnovers

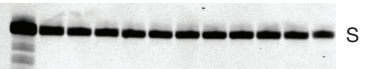

Figure $2 \mid$ Chemical synthesis yields an active RNA endonuclease

XNAzyme. a, Secondary structure of truncated FANAzyme FR17_6 (FR17_6min, purple), determined by RNA-SHAPE and RNA/FANA-DMS mapping (derived from a larger construct, Extended Data Fig. 5). Red indicates SHAPE reactive residues (RNA), blue circles indicate DMS-reactive (preferentially A or C) residues (RNA or FANA), dashed circles indicate marginal reactivity. The substrate $\mathrm{RNA}\left(\mathrm{NucS}^{\mathrm{R}}\right.$ _min) is a minimized version of the substrate for FR17_6. b, FR17_6min synthesized using FANA phosphoramidites (Extended Data Fig. 10) cleaves cognate RNA substrate

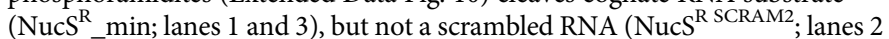
and 4$)$, with, c, essentially unchanged catalytic rate $\left(k_{\text {obs }}\right)$ at $25^{\circ} \mathrm{C}(n=3$; error bars, s.d.). d, FR17_6min (10 nM) can perform multiple turnover cleavage of RNA NucS ${ }^{\mathrm{R}}$ min $(1 \mu \mathrm{M})$

$10^{4}$-fold compared to the uncatalysed background reaction (RNA substrates $\operatorname{LigS1}{ }^{\mathrm{R}}+\mathrm{LigS}^{\mathrm{R}}$ hybridized to a 'splint' (complementary FANA template); $k_{\text {uncat }}=2 \times 10^{-8} \mathrm{~min}^{-1}$ ). Like the RNA endonuclease FANAzyme FR17_6, the activity of F2R17_1min is enhanced at basic $\mathrm{pH}\left(\mathrm{pH}_{\mathrm{opt}}=\right.$ 10.25; Extended Data Fig. 7e), as well as by $\mathrm{Mg}^{2+}$ (Extended Data Fig. 7f), for which only $\mathrm{Mn}^{2+}$ can be substituted (Extended Data Fig. 7d), consistent with a mechanism involving deprotonation and nucleophilic attack of the $3^{\prime}$ hydroxyl of $\mathrm{LigS1}^{\mathrm{R}}$ on the $\alpha$-phosphate of $5^{\prime} \mathrm{ppp}-\mathrm{LigS2}^{\mathrm{R}}$, analogous to, for example, the R3C ligase ribozyme ${ }^{23}$.

In the above examples, XNA catalysts cleave or ligate natural substrates (RNA, DNA). Next we sought to discover whether XNA catalysts could act on XNA substrates, establishing a fully synthetic catalytic system. We chose to select for XNA-XNA ligase activity with a view to its potential synthetic utility for the assembly of larger XNA oligomers (Extended Data Fig. 8). Again exploiting solid-phase FANA synthesis for substrate and primer strands, we synthesized an all-FANA library loosely patterned on the secondary structure of the DNA-ligase DNAzyme E47 ${ }^{24}$ (see Methods) and selected for ligation of the library $5^{\prime}$ hydroxyl group to a substrate activated with $3^{\prime}$ phosphorylimidazolide (pIm). After 4 rounds, we identified multiple FANA ligase FANAzymes (Extended Data Fig. 9). One of these, FpImR4_2 (41nt), was found to be a $\mathrm{Zn}^{2+}$-dependent metalloenzyme capable of XNA-XNA (FANA-FANA) ligation in a trimolecular reaction $\left(\operatorname{LigS1} 1^{\mathrm{F}}+\mathrm{LigS}^{\mathrm{F}}+\mathrm{FpImR} 4{ }_{2} \rightarrow \operatorname{LigP}^{\mathrm{F}}+\right.$ FpImR4_2; Fig. 4). The product (LigP $\left.{ }^{\mathrm{F}}\right)$ shows an identical SAX-HPLC profile to a 'mock' product synthesized by D4K polymerase (Extended Data Fig. 9c), suggesting the ligation proceeds with $3^{\prime}-5^{\prime}$ regioselectivity. Despite the higher reactivity of the activating group, uncatalysed FANA reactions with or without a complementary FANA splint yielded no detectable ligation of $\operatorname{LigS1}^{\mathrm{F}}$ and $\operatorname{LigS} 2^{\mathrm{F}}$ (Fig. 4b), even after incubation for several days.

Despite no apparent sequence or structural homology, as judged by DMS probing (Extended Data Fig. 5), FpImR4_2 and DNAzyme E47 may employ analogous catalytic strategies because they display a similar pH optimum $\left(\mathrm{pH}_{\mathrm{opt}}=7.25\right.$; Extended Data Fig. 9e), metal ion dependence $\left(\mathrm{Zn}^{2+}\right.$; Extended Data Fig. 9f) and catalytic rate (FpImR4_2 
a

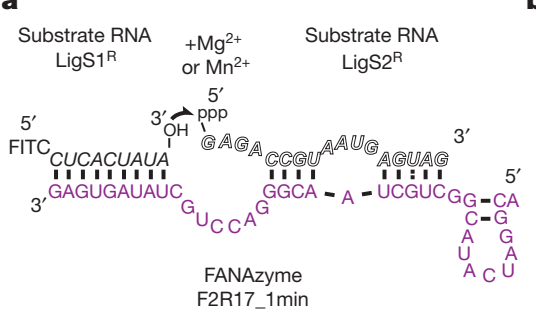

b

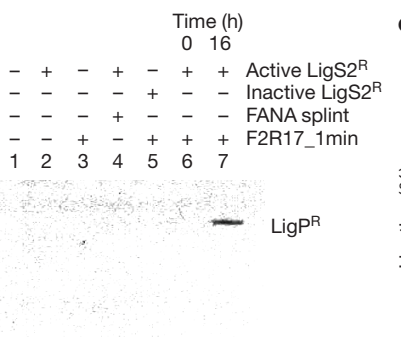

c

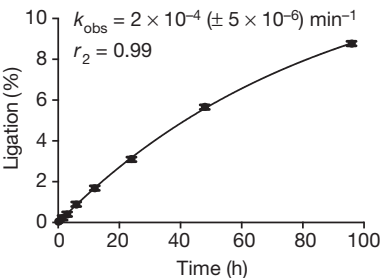

Figure 3 An RNA ligase XNAzyme (FANA). a, Putative secondary structure of truncated chemically synthesized FANAzyme (F2R17_1min, purple) that ligates RNA substrate $\operatorname{LigS} 1^{\mathrm{R}}$ to $\operatorname{LigS} 2^{\mathrm{R}}$, activated with $5^{\prime}$ triphosphate (ppp), in a trimolecular reaction in trans. $\mathbf{b}$, Urea-PAGE gel showing no significant product $\left(\mathrm{LigP}^{\mathrm{R}}\right)$ observed with: substrate $\mathrm{LigS1}^{\mathrm{R}}$ alone (lane 1), no XNAzyme (lane 2), no LigS2 ${ }^{\mathrm{R}}$ (lane 3), complementary FANA splint (lane 4), or LigS2 ${ }^{\mathrm{R}}$

$k_{\mathrm{obs}}=0.04 \mathrm{~min}^{-1}$ versus E47 $k_{\mathrm{obs}}=0.06 \mathrm{~min}^{-1}$ at $\left.35^{\circ} \mathrm{C}\right)^{24}$. However, unlike with E47, in the FpImR4_2 reaction, $\mathrm{Cu}^{2+}$ cannot substitute $\mathrm{Zn}^{2+}$, and $\mathrm{Mg}^{2+}\left(\right.$ or $\mathrm{Ca}^{2+}$ ) enhances activity (Extended Data Fig. 9d). Unlike RNA ligase FANAzyme F2R17_1, FpImR4_2 displays a relaxed recognition of substrate chemistry; although most efficient at FANA-FANA ligation, it can also ligate FANA-DNA, FANA-RNA, DNA-FANA as well as DNA-DNA (Extended Data Fig. 9g).

Finally, in order to explore the synthetic potential of XNA ligation, the substrate strands and the XNA ligase FANAzyme were adapted to lacking 5'ppp (lane 5); product formation is dependent on $\operatorname{LigS1}{ }^{\mathrm{R}}$, activated $\mathrm{LigS}^{\mathrm{R}}$ and XNAzyme (lanes 6 and 7). No product was detectable with combinations of RNA, DNA or FANA versions of LigS1 and (5'ppp)LigS2, except DNA LigS1 and RNA LigS2, which showed $\sim 1.5 \%$ ligation after $20 \mathrm{~h}$ (Extended Data Fig. $7 \mathrm{~g})$. c, Pre-steady state trimolecular reaction rate $\left(k_{\mathrm{obs}}\right)$ at $25^{\circ} \mathrm{C}(n=3$; error bars, s.d. $)$.

perform novel reactions. Modification of $\operatorname{LigS} 2^{\mathrm{F}}$ substrate to include the $\operatorname{LigS1} 1^{\mathrm{F}}$ sequence (that is, LigS2 $+1^{\mathrm{F}}$ ) and a $3^{\prime}$-phosphorylimidazolide activation group enabled iterative substrate addition, thus synthesizing FANA oligomers up to $100 \mathrm{nt}$ long (Fig. 4d). Modification of the FpImR4_2 substrate-binding strands allowed ligation of a variant of the FR17-6 RNA endonuclease from constituent fragments (see Methods), enabling XNAzyme-catalysed synthesis of another XNAzyme (Fig. 4e).

Synthesis, replication (via a DNA intermediate) and evolution of synthetic genetic polymers (XNAs) not found in nature has opened up new

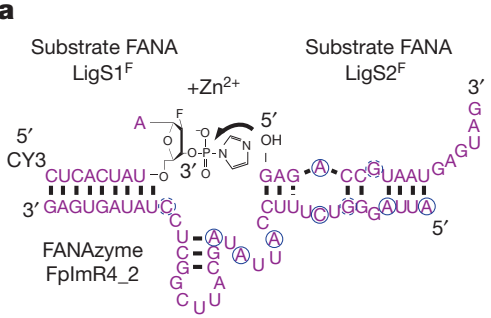

b

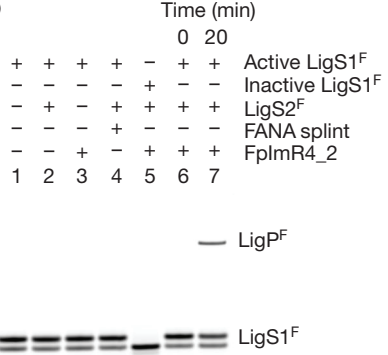

d $\quad$ Time (min) $0 \quad 510204080$
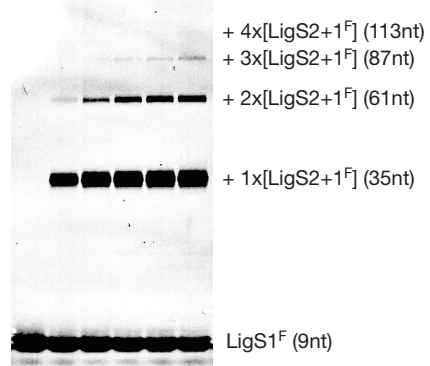

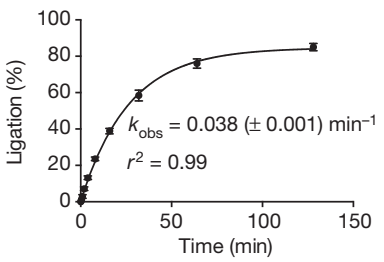
$++-\quad$ NuCS RSRAM2 -++ NucSVR

e FplmR4_2mut -
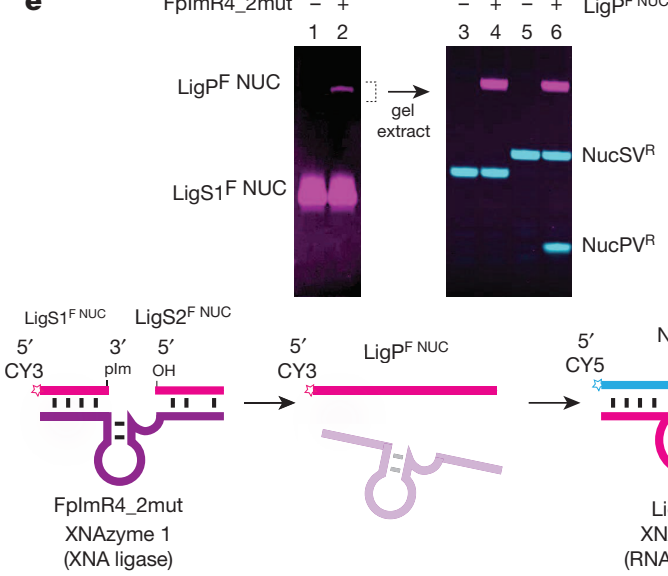

Figure $4 \mid$ XNA-XNA ligase XNAzyme (FANA) demonstrates catalysis without natural nucleic acids. a, Secondary structure (determined by DMS mapping, Extended Data Fig. 5) of chemically synthesized FANAzyme FpImR4_2, which ligates FANA LigS1 ${ }^{\mathrm{F}}$, activated with $3^{\prime}$ phosphorylimidazolide (pIm), to LigS2 ${ }^{\mathrm{F}}$ in trans. b, Urea-PAGE gel showing no product with: substrate $\operatorname{LigS1}^{\mathrm{F}}$ alone (lane 1), no XNAzyme (lane 2), no $\operatorname{LigS2}_{2}^{\mathrm{F}}$ (lane 3), splint (lane 4), or LigS1 ${ }^{\mathrm{F}}$ lacking 3'pIm (lane 5); product formation is dependent on LigS2 ${ }^{\mathrm{F}}$, activated LigS1 ${ }^{\mathrm{F}}$ and XNAzyme (lanes 6 and 7). c, Pre-steady state trimolecular reaction rate $\left(k_{\text {obs }}\right)$ at $35^{\circ} \mathrm{C}(n=3$; error bars, s.d.). d, Urea-PAGE gel showing FpImR4_2-catalysed oligomerization of XNA (FANA) substrates. Substrate LigS $2+1^{\mathrm{F}}$ is a $3^{\prime}$ pIm-activated substrate containing the sequences of both $\mathrm{LigS1}{ }^{\mathrm{F}}$ and $\mathrm{LigS} 2^{\mathrm{F}}$ above. e, Urea-PAGE gels and schematic diagram showing XNAzyme-catalysed assembly of an active XNAzyme. A variant XNA ligase (FpImR4_2mut) catalyses ligation (lane 2) of FANA substrates LigS1 ${ }^{\mathrm{F} \mathrm{NUC}}$ and $\mathrm{LigS2} 2^{\mathrm{F} \mathrm{NUC}}$. The product $\left(\mathrm{LigP}^{\mathrm{F} \mathrm{NUC}}\right)$ is a variant of XNAzyme FR17_6 min (Fig. 2), which cleaves RNA substrate $\mathrm{NucSV}^{\mathrm{R}}$ (lanes 5 and 6), but not scrambled RNA (NucS ${ }^{\mathrm{R} \text { SCRAM2 }}$ )(lanes 3 and 4$)$. 
sequence spaces for exploration, but their phenotypic richness remains to be determined. We have shown the discovery of catalysts (RNA endonucleases) in four such XNA sequence spaces (ANA, FANA, HNA, CeNA) and the elaboration of three different catalytic activities (RNA endonuclease, RNA ligase and XNA ligase) in one (FANA). These results indicate that properties such as catalysis (as well as heredity and evolution) are generalizable to a range of nucleic acid scaffolds and are likely to be emergent properties of many synthetic genetic polymers. This argues against a strong functional imperative for the chemistry of life's genetic systems.

Limitations in current XNA technology (for example, XNA-specific sequence biases, lower fidelity and sensitivity) contribute to library undersampling, genetic drift and reduced selection stringency, complicating comparisons of phenotypic richness of the respective XNAs with DNA and RNA sequence spaces. Nevertheless, we note that the FANA framework, with similar hybridization energetics and conformational analogy to $\mathrm{DNA}^{19}$, yielded the most active XNAzymes, while catalysts in other XNAs, which exhibit reduced (ANA) ${ }^{13}$ or enhanced (HNA and CeNA) duplex stability, as well as divergent helical conformations and dynamics ${ }^{7,25}$, showed slower rates. Substrate binding that is too weak or too strong, or conformational dynamics that are either too rapid or too slow, will reduce catalytic power by slowing conformational transitions required for catalysis and stabilizing inactive XNAzyme conformers. The evolutionary landscape of structurally more divergent XNAs may extend beyond the narrow parameters of DNA and RNA, suggesting that, for example, more effective HNA- or CeNAzymes might be discovered under non-physiological conditions. More work will be needed to resolve the question of whether life's reliance on RNA and DNA reflects a potential functional privilege of the natural polymers over unnatural XNAs in an ambient terrestrial environment ${ }^{9}$ or a predisposition of prebiotic chemistry.

Future advances in methodologies for the synthesis, replication and evolution of chemically ever more divergent genetic polymers should help to resolve these questions, providing a growing database of the molecular limits of chemical encoding and replication of information, while also yielding XNA catalysts (and ligands) that fully exploit their expanded range of physicochemical properties and biostability ${ }^{4,26-28}$ with potential applications ranging from medicine to nanotechnology.

Online Content Methods, along with any additional Extended Data display items and Source Data, are available in the online version of the paper; references unique to these sections appear only in the online paper.

Received 10 July; accepted 20 October 2014.

Published online 1 December 2014

1. Atkins, J. F., Gesteland, R. F. \& Cech, T. R. (eds) RNA Worlds (Cold Spring Harbor Laboratory, 2012)

2. Breaker, R. R. \& Joyce, G. F. A DNA enzyme that cleaves RNA. Chem. Biol. 1, 223-229 (1994).

3. Eschenmoser, A. Chemical etiology of nucleic acid structure. Science $\mathbf{2 8 4}$, 2118-2124 (1999)

4. Pinheiro, V. B. et al. Synthetic genetic polymers capable of heredity and evolution. Science 336, 341-344 (2012).

5. Noronha, A. M. et al. Synthesis and biophysical properties of arabinonucleic acids (ANA): circular dichroic spectra, melting temperatures, and ribonuclease $\mathrm{H}$ susceptibility of ANA.RNA hybrid duplexes. Biochemistry 39, 7050-7062 (2000).

6. Wilds, C. J. 2'-Deoxy-2'-fluoro- $\beta$-D-arabinonucleosides and oligonucleotides (2'FANA): synthesis and physicochemical studies. Nucleic Acids Res. 28, 3625-3635 (2000).

7. Herdewijn, P. Nucleic acids with a six-membered 'carbohydrate' mimic in the backbone. Chem. Biodivers. 7, 1-59 (2010).
8. Pinheiro, V. B. \& Holliger, P. The XNA world: progress towards replication and evolution of synthetic genetic polymers. Curr. Opin. Chem. Biol. 16, 245-252 (2012).

9. Benner, S. A., Ricardo, A. \& Carrigan, M. A. Is there a common chemical model for life in the universe? Curr. Opin. Chem. Biol. 8, 672-689 (2004).

10. Valadkhan, S. \& Manley, J. L. Splicing-related catalysis by protein-free snRNAs. Nature 413, 701-707 (2001).

11. Nissen, P., Hansen, J., Ban, N., Moore, P. B. \& Steitz, T. A. The structural basis of ribosome activity in peptide bond synthesis. Science 289, 920-930 (2000).

12. Joyce, G. F. Directed evolution of nucleic acid enzymes. Annu. Rev. Biochem. 73, 791-836 (2004).

13. Martín-Pintado, N. et al. The solution structure of double helical arabino nucleic acids (ANA and 2'F-ANA): effect of arabinoses in duplex-hairpin interconversion. Nucleic Acids Res. 40, 9329-9339 (2012).

14. Lilley, D. M. J. Mechanisms of RNA catalysis. Phil. Trans. R. Soc. Lond. B 366, 2910-2917 (2011).

15. Wilkinson, K. A., Merino, E. J. \& Weeks, K. M. Selective 2'-hydroxyl acylation analyzed by primer extension (SHAPE): quantitative RNA structure analysis at single nucleotide resolution. Nature Protocols 1, 1610-1616 (2006).

16. Homan, P. J. et al. Single-molecule correlated chemical probing of RNA. Proc. Natl Acad. Sci. USA 111, 13858-13863 (2014).

17. Santoro, S. W. \& Joyce, G. F. A general purpose RNA-cleaving DNA enzyme. Proc. Natl Acad. Sci. USA 94, 4262-4266 (1997).

18. Santoro, S. W. \& Joyce, G. F. Mechanism and utility of an RNA-cleaving DNA enzyme. Biochemistry 37, 13330-13342 (1998).

19. Minasov, G., Teplova, M., Nielsen, P., Wengel, J. \& Egli, M. Structural basis of cleavage by RNase $\mathrm{H}$ of hybrids of arabinonucleic acids and RNA. Biochemistry 39, 3525-3532 (2000)

20. Bartel, D. P.\& Szostak, J. W. Isolation of new ribozymes from a large pool of random sequences [see comment]. Science 261, 1411-1418 (1993).

21. Paul, N., Springsteen, G. \& Joyce, G. F. Conversion of a ribozyme to a deoxyribozyme through in vitro evolution. Chem. Biol. 13, 329-338 (2006).

22. Ekland, E. H., Szostak, J. W. \& Bartel, D. P. Structurally complex and highly active RNA ligases derived from random RNA sequences. Science 269, 364-370 (1995).

23. Rogers, J. \& Joyce, G. F. The effect of cytidine on the structure and function of an RNA ligase ribozyme. RNA 7, 395-404 (2001).

24. Cuenoud, B. \& Szostak, J. W. A. DNA metalloenzyme with DNA ligase activity. Nature 375, 611-614 (1995).

25. Lescrinier, E. et al. Solution structure of an HNA-RNA hybrid. Chem. Biol. 7, 719-731 (2000)

26. Dowler, T., Bergeron, D. \& Tedeschi, A. L. Improvements in siRNA properties mediated by 2'-deoxy-2'-fluoro- $\beta$-D-arabinonucleic acid (FANA). Nucleic Acids Res. 34, 1669-1675 (2006)

27. Hendrix, C. et al. 1',5'-Anhydrohexitol oligonucleotides: hybridisation and strand displacement with oligoribonucleotides, interaction with RNase $\mathrm{H}$ and HIV reverse transcriptase. Chemistry 3, 1513-1520 (1997).

28. Nauwelaerts, K., Fisher, M. \& Froeyen, M. Structural characterization and biological evaluation of small interfering RNAs containing cyclohexenyl nucleosides. J. Am. Chem. Soc. 129, 9340-9348 (2007)

Supplementary Information is available in the online version of the paper.

Acknowledgements This work was supported by the Medical Research Council (MRC) programme grant U105178804 (P. Holliger, A.I.T., V.B.P., A.S.M., S.P.-C., C.C.) and by grants from the European Science Foundation (ESF) and the Biotechnology and Biological Sciences Research Council (BBSRC) UK (09-EuroSYNBIO-OP-013) (P.H. A.I.T.), the European Union Framework (FP7/2007-2013 (P. Herdewijn), the European Research Council (ERC-2012 ADG_20120216/320683 (P. Herdewijn)), the US National Science Foundation (MCB-1121024 (K.M.W.)) and by an NSF Graduate Research Fellowship (DGE-1144081 (M.J.S.)).

Author Contributions A.I.T. and P. Holliger conceived and designed the experiments. A.I.T. performed XNAzyme selections and characterized XNAzymes with V.B.P., A.S.M., S.P.-C., C.C. V.B.P. generated the improved HNA synthetase. M.J.S. and K.M.W. performed and analysed SHAPE and DMS mapping experiments. P. Herdewijn synthesized hNTPs, ceNTPs and aGTP. All authors analysed data and co-wrote the paper.

Author Information Reprints and permissions information is available at www.nature.com/reprints. The authors declare no competing financial interests. Readers are welcome to comment on the online version of the paper. Correspondence and requests for materials should be addressed to P. Holliger (ph1@mrc-Imb.cam.ac.uk). 


\section{METHODS}

Nucleotides and oligonucleotides. Triphosphates of HNA (hNTPs), CeNA (ceNTPs) and ANA aGTP were synthesized and analysed as described previously ${ }^{4}$. Triphosphates of ANA (aATP, aCTP, aUTP) were obtained from TriLink BioTechnologies, FANA (faNTPs) from Metkinen Chemistry (Finland) and DNA (Illustra dNTPs) from GE Life Sciences (USA). Oligonucleotides were synthesized by Integrated DNA technologies (Belgium) or Sigma Aldrich (USA), unless stated otherwise. Triphosphorylated RNA (LigS2 ${ }^{\mathrm{R}}$ ) was obtained from Trilink BioTechnologies (USA). Mock_LigP ${ }^{\mathrm{R}}$ $\left[2^{\prime}-5^{\prime}\right]$ and Mock_LigP ${ }^{\mathrm{R}}\left[3^{\prime}-5^{\prime}\right]$ RNA standards were obtained from ChemGenes (USA). All oligonucleotides were purified by denaturing urea-PAGE and ethanol-precipitated from filtrates of freeze-thawed gel mash as described previously ${ }^{4}$.

Synthesis of XNAs. FANA and chimaeric DNA-FANA oligonucleotides were prepared either enzymatically (see below) or by solid-phase chemical synthesis using a Mermade4 instrument (BioAutomation, USA) with $1 \mu \mathrm{mol} \mathrm{scale} \mathrm{3'}$ phosphate (Synbase 1000, Link Technologies, UK) or universal (UnySupport 1000, Glen Research, USA) CPG supports. Phosphoramidites of DNA and all synthesis reagents were obtained from Link Technologies (UK), unless stated otherwise. The solid-phase synthesis method was adapted from Deleavey et al. ${ }^{29}$. Phosphoramidites of 2 ' fluoroarabinonucleosides (FANA), cyanine 3 fluorophore (CY3) or biotin-triethyleneglycol (BiotinTEG) were obtained from Glen Research (USA) and prepared as $0.15 \mathrm{M}$ solutions in anhydrous acetonitrile (ACN) (Sigma Aldrich, USA), those of DNA were prepared as $0.1 \mathrm{M}$ solutions. Phosphoramidites were activated with 0.3 M BTT (5-benzylthio- $1 \mathrm{H}$-tetrazole in $\mathrm{ACN}$ ), deblocking was performed with $3 \%$ trichloroacetic acid in dichloromethane, capping of failure sequences was performed with pyridine acetic anhydride and $10 \%$ methylimidazole in tetrahydrofuran, and oxidation was performed with $0.02 \mathrm{M}$ iodine oxidiser (Proligo series, Sigma Aldrich, USA). Coupling times were $600 \mathrm{~s}$ for all phosphoramidites, with the exception of CY3, BiotinTEG and the FANA guanosine phosphoramidite, which were allowed to couple for $900 \mathrm{~s}$. Deprotection and cleavage from CPG support was achieved by incubation in 3:1 $\mathrm{NH}_{4} \mathrm{OH}: \mathrm{EtOH}$ for $48 \mathrm{~h}$ at room temperature, then dried by speedvac. PAGE purified chemically synthesized FANA substrates and XNAzymes were analysed by mass spectrometry (Extended Data Fig. 10). For triphosphate addition to synthesized FANA (and DNA), the method described by Zlatev et al. ${ }^{30}$ was followed before deprotection and cleavage from the solid support.

All other XNAs were prepared enzymatically using polymerase mutants as described previously $y^{4}$; polymerases D4K for ANA and FANA, 6G12 for CeNA and 6G12 I521L (see below) for 1,5 anhydrohexitol nucleic acid (HNA), with the addition of $4 \%$ ET-SSB (NEB, USA). For preparation of all-XNA strands using polymerases (for example, for in trans XNAzyme reactions), either the appropriate FANA primer was used, or an RNA primer was used to synthesis an RNA-XNA chimaeric strand, which was then incubated in $0.8 \mathrm{M} \mathrm{NaOH}$ at $65^{\circ} \mathrm{C}$ for $1 \mathrm{~h}$ to completely hydrolyse the RNA portion. All XNA oligonucleotides were purified by denaturing urea-PAGE.

Preparation of single-stranded DNA, RNA and XNA. Biotinylated oligos were captured using Dynabeads MyOne Streptavidin C1 beads (Invitrogen/Life Technologies, USA ) in BWBS (10 mM Tris• $\mathrm{HCl} \mathrm{pH} \mathrm{7.4,1} \mathrm{M} \mathrm{NaCl,} \mathrm{0.1 \%} \mathrm{v/v} \mathrm{Tween} 20,1 \mathrm{mM}$ EDTA) for $1-2 \mathrm{~h}$ at room temperature or overnight at $4{ }^{\circ} \mathrm{C}$. Denaturation/elution of unbiotinylated strands was achieved by three washes in BWBS followed by rapid $(<1 \mathrm{~min}$ ) incubation in $0.1 \mathrm{M} \mathrm{NaOH}$ at room temperature. Where eluted strand was being prepared, $\mathrm{NaOH}$ supernatant was immediately neutralized in $1 \mathrm{M}$ Tris $\mathrm{pH}$ 7.4. Elution of biotinylated oligos from beads was achieved by three washes in $\mathrm{H}_{2} \mathrm{O}$, then incubation in either $\mathrm{H}_{2} \mathrm{O}$ for $2 \times 2 \mathrm{~min}$ at $80^{\circ} \mathrm{C}$, or PAGE loading buffer $(95 \%$ formamide, $10 \mathrm{mM}$ EDTA, $0.05 \%$ bromophenol blue) for $2 \times 2 \mathrm{~min}$ at $95{ }^{\circ} \mathrm{C}$.

Preparation of 6G12 I521L polymerase. We introduced the I521L mutation to the 6 G12 backbone by iPCR using primers RT520fo and RT521ba. PCR was carried out using Expand High Fidelity polymerase (Roche Diagnostics GmbH, Germany) as an initial incubation of $2 \mathrm{~min}$ at $95^{\circ} \mathrm{C}$ followed by $25 \times$ of $\left(30 \mathrm{~s} 95^{\circ} \mathrm{C}, 30 \mathrm{~s} 50^{\circ} \mathrm{C}\right.$, $18 \mathrm{~min} 68^{\circ} \mathrm{C}$ ) followed by a final extension of $10 \mathrm{~min} 68^{\circ} \mathrm{C}$. Amplified DNA was purified (QIAquick PCR purification kit, Qiagen $\mathrm{GmbH}$, Germany) according to the manufacturer's recommendations and restricted with BsaI and DpnI (New England Biolabs Inc., Massachusetts, USA). Reactions were again purified (QIAquick PCR purification kit) and ligated with T4 DNA ligase (NEB, USA). Ligated plasmids were transformed into $E$. coli NEB 10- $\beta$ cells (NEB, USA), and isolated transformants were checked by DNA sequencing (Source Biosciences, UK).

A transformant with the correct sequence was expressed and purified as previously described ${ }^{4}$ and used to determine the impact of the additional mutation on the fidelity and processivity of $6 \mathrm{G} 12$. The resulting $6 \mathrm{G} 12 \mathrm{I} 521 \mathrm{~L}$ polymerase had a different divalent cation optimum and could synthesize HNA in the absence of $\mathrm{Mn}^{2+}$ ions, in reactions carried out with $3 \mathrm{mM} \mathrm{Mg}^{2+}$. $6 \mathrm{G} 12 \mathrm{I} 521 \mathrm{~L}$ was more processive than 6G12 alone and could synthesize HNA at higher fidelities (aggregate DNA $\rightarrow \mathrm{HNA} \rightarrow$ DNA fidelity: $3.0 \times 10^{-3}-$ experiment carried out as described previously $y^{4}$ ).

Preparation of FANA phosphorylimidazolide oligonucleotides. Preparation of phosphorylimidazolide oligonucleotides was adapted from a method used by Orgel and others ${ }^{31} .3^{\prime}$ phosphorylated FANA or DNA was prepared by solid-phase chemical synthesis (see above) and re-suspended to $100 \mu \mathrm{M}$ in $0.5 \mathrm{M}$ imidazole (pH 6.0). $50 \mu \mathrm{l}$ oligo/imidazole solution was added to $6.5 \mu \mathrm{mol}$ solid 1-ethyl-3-[3-dimethylaminopropyl]carbodiimide hydrochloride (EDC) (Pierce Biotechnology/Thermo, USA) and incubated at room temperature for $2 \mathrm{~h}$. Oligos were desalted using Amicon 3,000 MW cut-off spin filters (Merck Millipore, USA). Purification of (and analysis of reactions involving) all phosphorylimidazolide oligos were performed using Trisfree urea-PAGE gels run using $10 \mathrm{mM} \mathrm{NaOH}, \mathrm{pH}$ adjusted to 8.5 with boric $\mathrm{acid}^{32}$. FANA phosphorylimidazolides were analysed by mass spectrometry, phosphatase protection and urea-PAGE mobility (Extended Data Fig. 10).

XNAzyme selections. General schemes for selections are shown in Extended Data Figs 1, 6 and 8. Purified single-stranded libraries and substrates were annealed by incubation at $80^{\circ} \mathrm{C}$ for $60 \mathrm{~s}$, then allowed to cool to room temperature over $5 \mathrm{~min}$, except for phosphorylimidazolide oligos, which were not annealed. Substrates and enzymes were incubated separately in reaction buffer for $5 \mathrm{~min}$ at reaction temperature, then mixed to start reactions. For selection of RNA ligase and endonuclease XNAzymes, reactions were performed at $17^{\circ} \mathrm{C}$ in $30 \mathrm{mM}$ HEPES (pH 8.5), $150 \mathrm{mM}$ $\mathrm{KCl}, 25 \mathrm{mM} \mathrm{MgCl}_{2}$ and $0.5 \mathrm{U} \mathrm{\mu l}^{-1} \mathrm{RNasein}$ RNase inhibitor (Promega, USA). For selection of XNA (FANA) ligase XNAzymes, reactions were performed at $35^{\circ} \mathrm{C}$ in $30 \mathrm{mM}$ HEPES (pH 7.2), $150 \mathrm{mM} \mathrm{KCl}, 25 \mathrm{mM} \mathrm{MgCl}_{2}$ and $1 \mathrm{mM} \mathrm{ZnCl}_{2}$. In general, $\sim 1 \mathrm{nmol}$ of starting library was prepared and reacted at $10 \mu \mathrm{M}$ with equimolar substrate for 5 days. For rounds 2-17, 10-50 pmol XNA pools were prepared and reacted at $1 \mu \mathrm{M}$ over steadily decreasing reaction times, settling on $30 \mathrm{~min}$ in rounds 15-17. In RNA endonuclease XNAzyme selections, the three libraries for each XNA (fully degenerate N40 library, and the ' $8-17$ ' and ' $10-23$ ' patterned libraries) were synthesized separately, but pooled after round 5 .

All XNA reverse transcriptions (using polymerase RTI521L) were performed as described previously for HNA aptamer selections ${ }^{4}$, but without a polyA tailing step and using $0.2 \mu \mathrm{M}$ RT primer Tag4test7_2Me (or a version with 5' BiotinTEG), which contains 2'O-methyl RNA modifications to improve annealing. First-stand cDNA was amplified by a two-step nested PCR strategy (see Extended Data Figs 1, 6 and 8). The first 'out-nested' RT + PCRs used $0.5 \mu \mathrm{M}$ primers and a mixture of OneTaq Hot

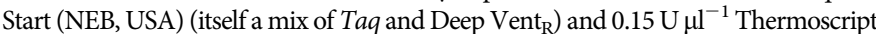
(Invitrogen/Life Technologies, USA) polymerases, which is able to transcribe $2^{\prime} \mathrm{O}$-methyl RNA, in $20 \mathrm{mM}$ Tris- $\mathrm{HCl}\left(\mathrm{pH} 8.9\right.$ at $25^{\circ} \mathrm{C}$ ), $22 \mathrm{mM} \mathrm{NH}_{4} \mathrm{Cl}, 22 \mathrm{mM}$ $\mathrm{KCl}, 0.06 \%$ IGEPAL CA-630, 0.05\% Tween $20,4 \mathrm{mM} \mathrm{MgCl}_{2}$ and $200 \mu \mathrm{M} \mathrm{dNTPs.} \mathrm{Cy-}$ cling conditions were $80^{\circ} \mathrm{C}$ for $30 \mathrm{~s}, 52^{\circ} \mathrm{C}$ for $30 \mathrm{~s}, 72{ }^{\circ} \mathrm{C}$ for $15 \mathrm{~min}, 94^{\circ} \mathrm{C}$ for $1 \mathrm{~min}$, $20-35 \times\left[94^{\circ} \mathrm{C}\right.$ for $30 \mathrm{~s}, 54^{\circ} \mathrm{C}$ for $30 \mathrm{~s}, 72^{\circ} \mathrm{C}$ for $\left.30 \mathrm{~s}\right], 72^{\circ} \mathrm{C}$ for $2 \mathrm{~min}$. Following the first PCR, primers were digested using ExoSAP (Ambion/Life Technologies, USA), which was then heat inactivated, according to the manufacturer's instructions. Second step ('in-nest') PCRs used using $1 \mu$ l of unpurified out-nest PCR product as template in a $50 \mu \mathrm{l}$ reaction using OneTaq Hot Start master mix (NEB, USA) and cycling conditions $94^{\circ} \mathrm{C}$ for $1 \mathrm{~min}, 10-20 \times\left[94^{\circ} \mathrm{C}\right.$ for $30 \mathrm{~s}, 54^{\circ} \mathrm{C}$ for $30 \mathrm{~s}, 72{ }^{\circ} \mathrm{C}$ for $\left.30 \mathrm{~s}\right], 72^{\circ} \mathrm{C}$ for $2 \mathrm{~min}$. Reactions were analysed by electrophoresis on $4 \%$ NGQT-1000 agarose (Thistle Scientific, UK) gels containing GelStar stain (Lonza, Switzerland). Bands of appropriate size were purified using a gel extraction kit (Qiagen, Netherlands) as per manufacturer's instructions. Purified DNA was used as the polyclonal template for either sequencing library PCR (see below) or large scale preparative PCR (2 ml) for generation of DNA templates for XNA synthesis. Prep PCR were performed with $1 \mu \mathrm{M}$ primers using $0.05 \mathrm{U}^{-1}{ }^{-1}$ SUPER Taq in 1 X buffer (HT Biotechnology, $\mathrm{UK}$ ) with $0.125 \mu \mathrm{M}$ dNTPs. Cycling conditions were the same as the second step PCR above. Single-stranded DNA templates were isolated using streptavidin beads (see above) and ethanol-precipitated before further use.

XNAzyme reactions. Purified XNAzymes and substrates were annealed as described above and reacted under selection conditions unless stated otherwise, in DNAor protein- (for 3' $\mathrm{pIm}$ reactions) LoBind tubes (Eppendorf, Germany). In $\mathrm{pH}$ titration experiments, buffer was substituted for $50 \mathrm{mM}$ EPPS (pH 6.5-8.75), CHES (pH 9.010.0 ) or CAPS ( $\mathrm{pH} 10.25-11.0)$. For determination of pseudo first-order reaction rate $\left(k_{\mathrm{obs}}\right)$ under single-turnover pre-steady-state $\left(K_{\mathrm{m}} / k_{\mathrm{cat}}\right)$ conditions, a fivefold excess of enzyme $(5 \mu \mathrm{M})$ was incubated in trans with either fluorophore-labelled $1 \mu \mathrm{M}$ NucS (nuclease substrate), or fluorophore-labelled $1 \mu \mathrm{M} \mathrm{LigS1} \mathrm{(ligase} \mathrm{substrate} \mathrm{1)} \mathrm{and} 5 \mu \mathrm{M}$ LigS2 (ligase substrate 2). RNA endonuclease and ligase reactions were performed in $30 \mathrm{mM}$ EPPS (pH 8.5), $150 \mathrm{mM} \mathrm{KCl}, 50 \mathrm{mM} \mathrm{MgCl}_{2}$ at $25^{\circ} \mathrm{C}$. XNA ligase reactions were performed in $30 \mathrm{mM} \mathrm{HEPES} \mathrm{(pH} \mathrm{7.5),} 150 \mathrm{mM} \mathrm{KCl}, 50 \mathrm{mM} \mathrm{MgCl}_{2}, 1 \mathrm{mMZnCl}_{2}$ at $35^{\circ} \mathrm{C}$. Reactions were stopped at different time points by addition of $95 \%$ formamide, $20 \mathrm{mM}$ EDTA and cooling on dry ice. Reactions were separated by urea-PAGE and fluorophores visualized using a Typhoon Trio imager (GE Life Sciences, UK). The fraction of reaction product to substrate was quantified using ImageQuant TL software (GE Life Sciences, UK) and mean data from three independent reactions (except for CeNAzyme CeR16_3, for which only two data sets were collected) were fitted to equation (1) using Prism 6.0b (GraphPad, USA):

$$
P(t)=P_{\infty}\left(1-\mathrm{e}^{-k_{\text {obs }} t}\right)
$$

where $P(t)$ is the percentage of cleaved or ligated RNA or XNA (FANA) at time $t, P_{\infty}$ is the apparent reaction end point and $k_{\mathrm{obs}}$ is the observed rate constant. For magnesium titration experiments, data were fitted to equation (2): 


$$
P(t)=P_{\infty} \times \frac{\left[\mathrm{Mg}^{2+}\right]}{K_{\mathrm{m}}+\left[\mathrm{Mg}^{2+}\right]}
$$

where $P(t)$ is the percentage of cleaved or ligated RNA or XNA (FANA) at time $t, P_{\infty}$ is the apparent reaction end point and $K_{\mathrm{m}}$ is the apparent Michaelis constant.

For FR17_6min multiple turnover catalysis, $1 \mu \mathrm{MNucSR}$ min(AG) was reacted with $10 \mathrm{nM}$ FR217_6min at $25^{\circ} \mathrm{C}$ in $30 \mathrm{mM}$ HEPES (pH 8.5), $150 \mathrm{mM} \mathrm{KCl}, 50 \mathrm{mM} \mathrm{MgCl}_{2}$. DNAzyme 8-17 synthesized as XNAs $(5 \mu \mathrm{M})$ was reacted with substrate NucS ${ }_{-}^{\mathrm{R}}$ AG $(1 \mu \mathrm{M})$ for $1 \mathrm{~h}$ at $37^{\circ} \mathrm{C}$ in $30 \mathrm{mM}$ HEPES (pH 8.5), $150 \mathrm{mM} \mathrm{NaCl}, 50 \mathrm{mM} \mathrm{MgCl}$. For characterization of bivalent metal ion requirements of selected XNAzymes, bimolecular (FR17_6min) or trimolecular (F2R17_1min and FpImR4_2) reactions were performed under conditions used to determine $k_{\text {obs }}$ with $\mathrm{MgCl}_{2}$ and/or $\mathrm{ZnCl}_{2}$ substituted by chlorides of the metals of the Irving-Williams series $(100 \mu \mathrm{M}-50 \mathrm{mM})$.

Deep sequencing. Amplified polyclonal cDNA from XNA selections was prepared for deep sequencing by the Illumina Miseq method by appending the bridge-amplification sequences by PCR. Sequencing library generating PCR reactions were performed with OneTaq Hot Start master mix (NEB, USA) with $10 \mathrm{ng}$ per $50 \mu$ l gel-purified polyclonal template DNA (see above), $0.1 \mu \mathrm{M}$ primers (P5_P2 and P3_Test7-2) and cycling conditions $94^{\circ} \mathrm{C}$ for $1 \mathrm{~min}, 10 \times\left[94^{\circ} \mathrm{C}\right.$ for $30 \mathrm{~s}, 56^{\circ} \mathrm{C}$ for $30 \mathrm{~s}, 72^{\circ} \mathrm{C}$ for $\left.30 \mathrm{~s}\right], 72^{\circ} \mathrm{C}$ for $2 \mathrm{~min}$. Sequencing library DNA was purified using a PCR purification kit (Qiagen, Netherlands), then a $12 \mathrm{pM}$ sample of pooled libraries plus $20 \% \mathrm{PhiX}$ control (Illumina, UK) was denatured and sequenced (single-end read, 75 cycles) using a MiSeq reagent kit and instrument (Illumina, UK) according to manufacturer's instructions. Libraries were barcoded using variants of the P5_P2 primer containing $6 \mathrm{nt}$ sequences from the NEXTflex series (Illumina, UK). Data were analysed using the Galaxy server ${ }^{33-35}$ and sequences ordered by abundance.

Analysis of oligonucleotide phosphorylation. The presence or absence of $3^{\prime}$ or $5^{\prime}$ phosphates on RNA cleavage products, and the protection of $3^{\prime}$ phosphates on FANA ligase substrates by formation of phosphorylimidazolides, was assayed by urea-PAGE gel shift following incubation in rAPid alkaline phosphatase (Roche, Switzerland) or T4 polynucleotide kinase (NEB, USA) in manufacturer's buffers for $30 \mathrm{~min}$ at $37^{\circ} \mathrm{C}$. Hydrolysis of cyclic phosphates was achieved by incubation in $10 \mathrm{mM}$ glycine $\mathrm{pH} 2.5$ for $10 \mathrm{~min}$ at room temperature. Partial alkaline hydrolysis of RNA substrates (denoted by ${ }^{-} \mathrm{OH}$ ) was achieved by incubation at $90^{\circ} \mathrm{C}$ in $50 \mathrm{mM}$ sodium carbonate buffer (pH 9.2) for $10 \mathrm{~min}$. Partial RNase T1 digestion was achieved by incubation at $55^{\circ} \mathrm{C}$

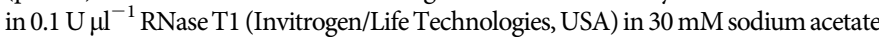
(pH 5) for $10 \mathrm{~min}$, then stopped in $7 \mathrm{M}$ urea $1.5 \mathrm{mM}$ EDTA.

Analysis of oligonucleotide mass by MALDI-ToF mass spectrometry. Oligo samples, $0.75 \mu \mathrm{l}$ in water, were spotted onto a MALDI target followed by $0.75 \mu \mathrm{l}$ of 3 hydroxypicolinic acid. Some oligo samples were vacuum dried, resuspended in $25 \mu \mathrm{l}$, 0.1 M TEAA (triethylammonium acetate) and desalted using a zip-tip C18 (Merck Millipore, USA). The zip-tip C18 was washed $3 \times 10 \mu \mathrm{l}$ of $0.1 \mathrm{M}$ TEAA and then $3 \times 10 \mu \mathrm{l}$ water. Next, the oligo was eluted directly onto a MALDI target with $5 \mu \mathrm{l}$ of 3-hydroxypicolinic acid. All mass spectrometric measurements were carried out in positive ion mode on an Ultraflex III TOF-TOF instrument (Bruker Daltonik, Bremen, Germany).

Analysis of oligonucleotide linkage isomers by SAX-HPLC. RNA and FANA ligation products were analysed by strong anion exchange chromatography (SAX-HPLC) using a Varian Prostar system (Agilent, USA) with a DNAPac PA200 column (Dionex/ Thermo, USA) under conditions sufficient to resolve linkage regioisomers ${ }^{36}: 10 \mathrm{nM}$ sodium phosphate buffer ( $\mathrm{pH} 11.5$ ), gradient $0.4 \mathrm{M}$ to $1.4 \mathrm{M} \mathrm{NaCl}$ over $30 \mathrm{~min}$, flow rate $1.5 \mathrm{ml} \mathrm{min}^{-1}$. Fluorescence was detected using a 122 fluorometer (Gilson, USA) set to excitation $488 \mathrm{~nm}$, emission $520 \mathrm{~nm}$ for carboxyfluorescein (6FAM)-labelled RNA, and emission $550 \mathrm{~nm}$, excitation $570 \mathrm{~nm}$ for cyanine 3 (CY3)-labelled FANA. Chemical probing of XNAzymes and secondary structure prediction. Selective 2 'hydroxyl acylation analysed by primer extension (SHAPE) structure probing experiments were performed on RNA endonuclease XNAzyme (FANA) FR17_6 using a chimaeric RNA-FANA construct, FR17_6wilk, prepared using primer SHAPE_Nucprim and template FR17_6wilk_temp. The construct contains sequences of $\mathrm{NucS}^{\mathrm{R}}$ (RNA) and FR17_6 (FANA) flanked by $5^{\prime}$ and $3^{\prime}$ structure cassette sequences from Wilkinson et al. ${ }^{15}$, with a $2^{\prime}$-O-methyl RNA modification at adenine 11 . For the XNA ligase XNAzyme (FANA) FpImR4_2, an analogous construct, FpImR4_2wilk, was prepared by ligation of $1 \mu \mathrm{M}$ modified FANA substrate LigS1wilk $\mathrm{F}^{\mathrm{F}}$ to an equimolar concentration of a version of FpImR4_2 with LigS2 $2^{\mathrm{F}}$ in cis (prepared by LigS2 ${ }^{\mathrm{F}}$-primed FANA synthesis on template FpImR4wilk_temp) for $2 \mathrm{~h}$ at $35^{\circ} \mathrm{C}$ in $30 \mathrm{mM}$ HEPES (pH 7.2), $150 \mathrm{mM} \mathrm{KCl}, 25 \mathrm{mM} \mathrm{MgCl}_{2}$ and $1 \mathrm{mM} \mathrm{ZnCl}_{2}$. FANA constructs $\left(1 \mu \mathrm{M}\right.$ in $\left.8 \mu \mathrm{H} \mathrm{H}_{2} \mathrm{O}\right)$ were denatured at $80^{\circ} \mathrm{C}$ for $1 \mathrm{~min}$, incubated at room temperature for $5 \mathrm{~min}$, treated with $1 \mu \mathrm{l} 10 \times$ SHAPE folding buffer ( $500 \mathrm{mM}$ EPPS (pH 8.2), $1.5 \mathrm{M} \mathrm{KCl}, 250 \mathrm{mM}$ $\mathrm{MgCl}_{2}$ ), and allowed to fold at $17^{\circ} \mathrm{C}$ for $20 \mathrm{~min}$. After folding, FANA constructs were treated with 1-methyl-7-nitroisatoic anhydride $(1 \mu \mathrm{l}, 100 \mathrm{mM}$ in neat DMSO) and incubated at $17^{\circ} \mathrm{C}$ for $15 \mathrm{~min}$. No-reagent control reactions were performed with $1 \mu \mathrm{l}$ neat DMSO. Denaturing control reactions were performed as described previously ${ }^{37}$. After modification, FANA constructs were purified with a G-50 spin column (GE Healthcare). cDNA was generated using SuperScript II reverse transcriptase (Life Technologies) under SHAPE-MaP conditions ${ }^{37}$.

Dimethyl sulphate (DMS) modification was adapted from the RING-MaP approach ${ }^{16}$. FANA constructs (nuclease: $1 \mu \mathrm{M}$ in $5 \mu \mathrm{l} \mathrm{H}_{2} \mathrm{O}$, ligase: $0.5 \mu \mathrm{M}$ in $5 \mu \mathrm{l}$ $\mathrm{H}_{2} \mathrm{O}$ ) were annealed as described above and treated with $4 \mu \mathrm{l} 2.5 \times$ DMS folding buffer $\left(750 \mathrm{mM}\right.$ cacodylate $\left.\mathrm{pH} 7.0,25 \mathrm{mM} \mathrm{MgCl}_{2}\right)$. Folded FANA constructs were treated with DMS $\left(1 \mu \mathrm{l}, 1.7 \mathrm{M}\right.$ in absolute ethanol), incubated at $17^{\circ} \mathrm{C}$ for $6 \mathrm{~min}$, quenched with $10 \mu \mathrm{l}$ neat 2-mercaptoethanol, and purified with a G-50 spin column. No-reagent control reactions were performed with $1 \mu \mathrm{l}$ absolute ethanol. cDNA was generated using RT521K polymerase as described previously ${ }^{4}$. Briefly, $5 \mathrm{pmol}$ FANA construct and 10 pmol primer were denatured for $1 \mathrm{~min}$ at $95^{\circ} \mathrm{C}$, chilled on ice, and incubated with $\sim 2 \mu \mathrm{g} \mathrm{ml}^{-1} \mathrm{RT} 521 \mathrm{~K}$ and $0.2 \mathrm{mM}$ dNTPs in $1 \times$ ThermoPol buffer (New England Biolabs) at $65^{\circ} \mathrm{C}$ for $4 \mathrm{~h}$. cDNA from reverse transcription reactions was purified with G-50 spin columns. SHAPE- and DMS-MaP sequencing libraries were created using the targeted gene-specific approach ${ }^{37}$, with minor changes: PCR 1 was performed for 23 cycles, $98^{\circ} \mathrm{C}$ for $30 \mathrm{~s}, 23 \times\left[98^{\circ} \mathrm{C}\right.$ for $10 \mathrm{~s}$, $68{ }^{\circ} \mathrm{C}$ for $30 \mathrm{~s}, 72{ }^{\circ} \mathrm{C}$ for $20 \mathrm{~s}$ ], $72{ }^{\circ} \mathrm{C}$ for $2 \mathrm{~min}$, and PCR 2 was performed for $7 \mathrm{cycles}$, using $1 \mu \mathrm{l}$ of unpurified PCR 1 product as template in a $50 \mu \mathrm{l}$ reaction. Purified libraries were pooled and sequenced with an Illumina MiSeq, generating data sets of $2 \times 150$ paired-end reads. Sequencing reads were aligned to reference sequences and per-nucleotide mutation rates, excluding primer-binding sites, were calculated using the SHAPE-MaP analysis pipeline. SHAPE reactivities were calculated for RNA nucleotide ${ }^{37}$; FANA nucleotides were excluded from SHAPE analysis. DMS reactivities for all nucleotides were calculated by subtracting the mutation rate of the no-reagent control from the mutation rate of DMS-modified FANAzymes at each position. SHAPE and DMS reactivity profiles were normalized by the ' $2 \%$ 8\%' method ${ }^{38}$. The FR17_6FANAzyme secondary structure model is the only structure predicted using ShapeKnots ${ }^{39}$, incorporating pseudo-free energy constraints derived from SHAPE reactivities. All other XNAzyme secondary structure models were predicted using ViennaRNA (version 2.1.6 ${ }^{40}$ or $_{\text {mfold }}^{41}$. The FpImR4_2 structure was further manually curated using DMS reactivity data. Oligonucleotide sequences can be found in Supplementary Table 1.

29. Deleavey, G. F. et al. Synergistic effects between analogs of DNA and RNA improve the potency of siRNA-mediated gene silencing. Nucleic Acids Res. 38, 4547-4557 (2010).

30. Zlatev, I., Manoharan, M., Vasseur, J.-J.\& Morvan, F. Solid-phase chemical synthesis of 5'-triphosphate DNA, RNA, and chemically modified oligonucleotides. In Current Protocols in Nucleic Acid Chemistry http://dx.doi.org/10.1002/ 0471142700.nc0128s50 (Wiley \& Sons, 2001).

31. Chu, B. C., Wahl, G. M. \& Orgel, L. E. Derivatization of unprotected polynucleotides. Nucleic Acids Res. 11, 6513-6529 (1983)

32. Brody, J. R. \& Kern, S. E. Sodium boric acid: a Tris-free, cooler conductive medium for DNA electrophoresis. Biotechniques 36, 214-216 (2004).

33. Goecks, J., Nekrutenko, A., Taylor, J. \& The Galaxy Team. Galaxy: a comprehensive approach for supporting accessible, reproducible, and transparent computational research in the life sciences. Genome Biol. 11, R86 (2010).

34. Blankenberg, D. et al. Galaxy: a web-based genome analysis tool for experimentalists. In Current Protocols in Molecular Biology Ch. 19, Unit 19.10.1-21 (2010).

35. Giardine, B. et al. Galaxy: a platform for interactive large-scale genome analysis. Genome Res. 15, 1451-1455 (2005).

36. Bowler, F. R. et al. Prebiotically plausible oligoribonucleotide ligation facilitated by chemoselective acetylation. Nature Chem. 5, 383-389 (2013).

37. Siegrried, N. A., Busan, S., Rice, G. M., Nelson, J. A. E. \& Weeks, K. M. RNA motif discovery by SHAPE and mutational profiling (SHAPE-MaP). Nature Methods $\mathbf{1 1}$ 959-965 (2014).

38. Mortimer, S. A. \& Weeks, K. M. A. Fast-acting reagent for accurate analysis of RNA secondary and tertiary structure by SHAPE chemistry. J. Am. Chem. Soc. 129, 4144-4145 (2007)

39. Hajdin, C. E. et al. Accurate SHAPE-directed RNA secondary structure modeling, including pseudoknots. Proc. Natl Acad. Sci. USA 110, 5498-5503 (2013).

40. Lorenz, R. et al. ViennaRNA Package 2.0. Algorithms Mol. Biol. 6, 26 (2011).

41. Zuker, M. Mfold web server for nucleic acid folding and hybridization prediction. Nucleic Acids Res. 31, 3406-3415 (2003). 

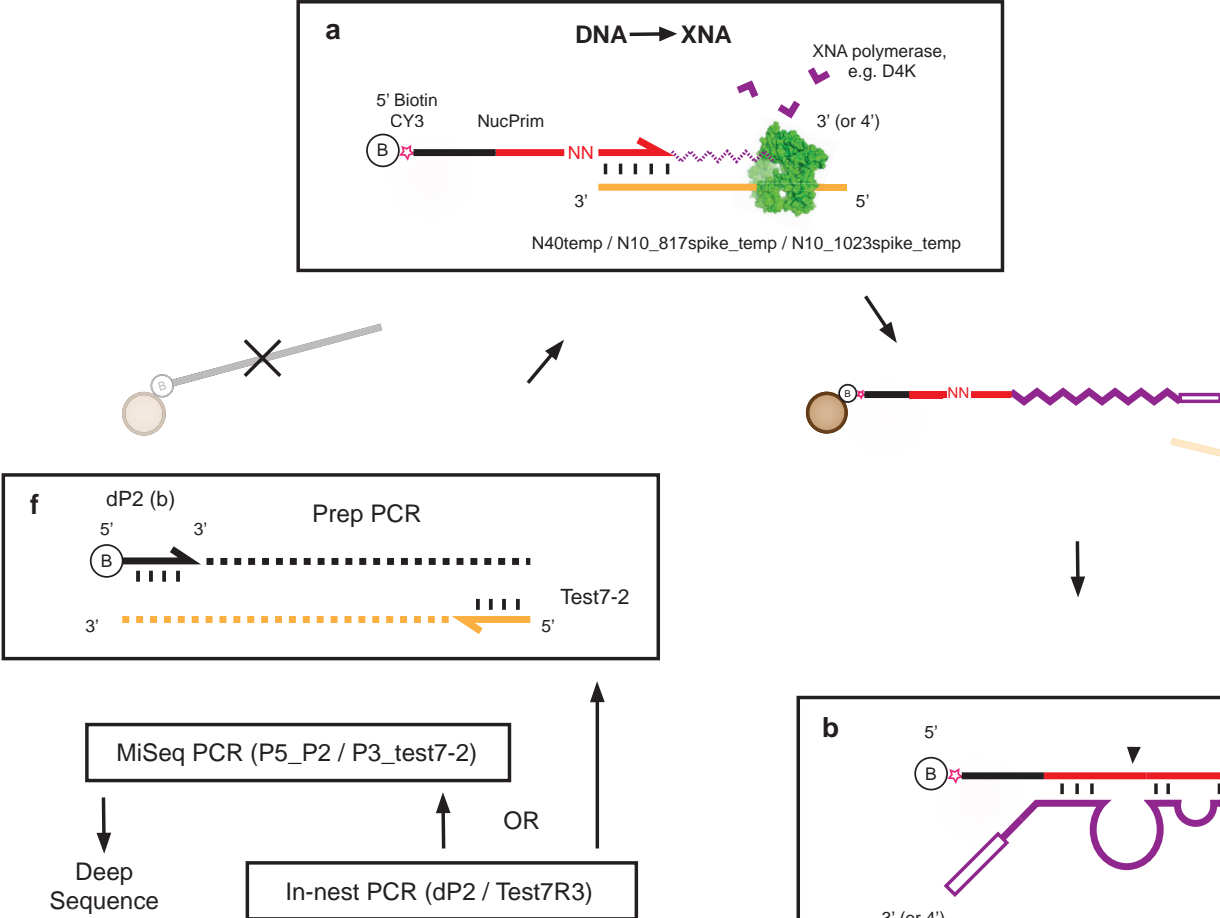

e

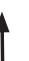

Out-nest PCR (dP2 / tag4)
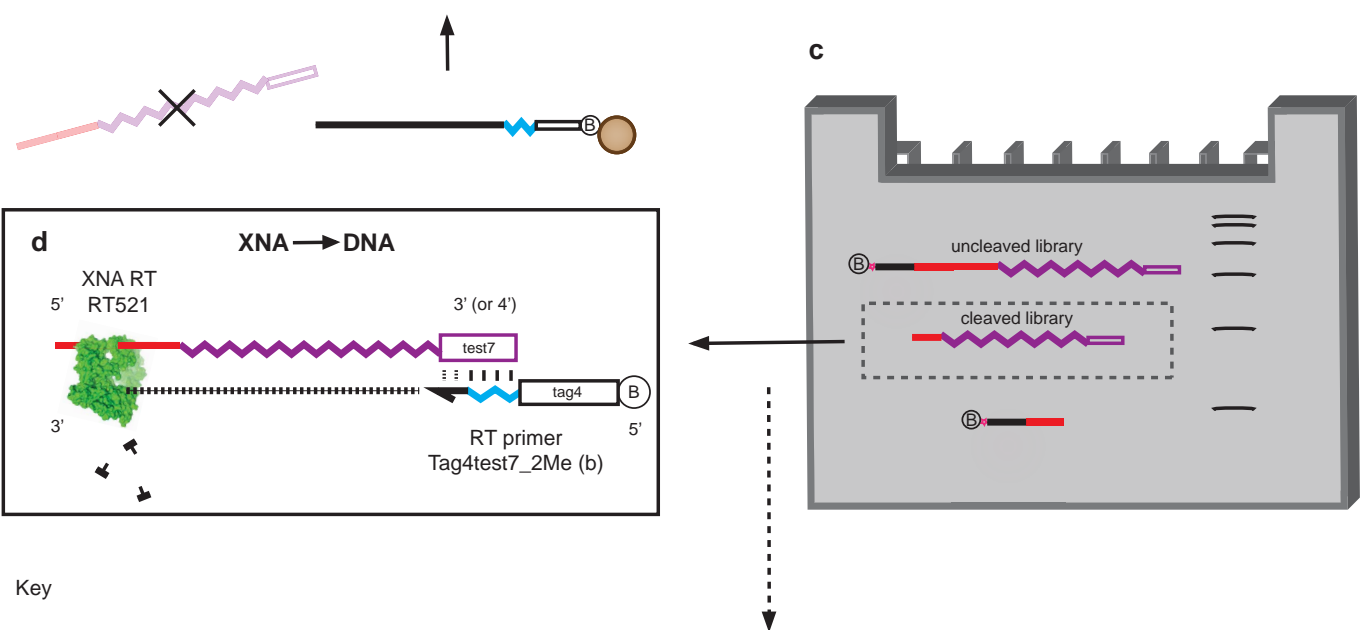

Key

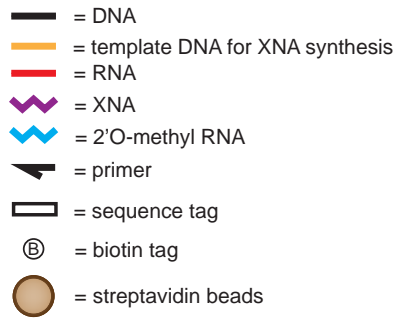

Extended Data Figure $1 \mid$ Selection scheme for RNA endonuclease XNAzymes. a, XNA library preparation using DNA-dependent XNA polymerases, templated using N40temp, N10_817spike_temp, or N10_1023spike_temp DNA oligonucleotides (see Supplementary Table 1) primed by a biotinylated chimaeric DNA-RNA primer (NucPrim), which serves as substrate for RNA cleavage in cis. Libraries are captured by streptavidin beads, allowing denaturation and removal of DNA templates. b, Single-stranded libraries are annealed and incubated in reaction buffer (see Methods), successful XNAzymes cleave the biotinylated RNA substrate in cis. c, Size separation of reacted XNA pools using denaturing polyacrylamide electrophoresis (urea-PAGE). Cleaved XNA pools are gel-extracted (indicated by dashed box) and incubated with streptavidin beads in order to capture and discard any uncleaved carry-over (indicated by dashed arrow). d, Reverse transcription of isolated, cleaved XNA pools using XNA-dependent DNA polymerase RT521L (that is, XNA $\rightarrow$ cDNA). e, Amplification of transcribed cDNA by successive PCR reactions, using the primers indicated (see Supplementary Table 1). f, PCR reaction generating templates for XNA synthesis for further rounds of selection. See Methods for details. Solid crosses indicate removal of denatured strands using streptavidin bead capture. 
b

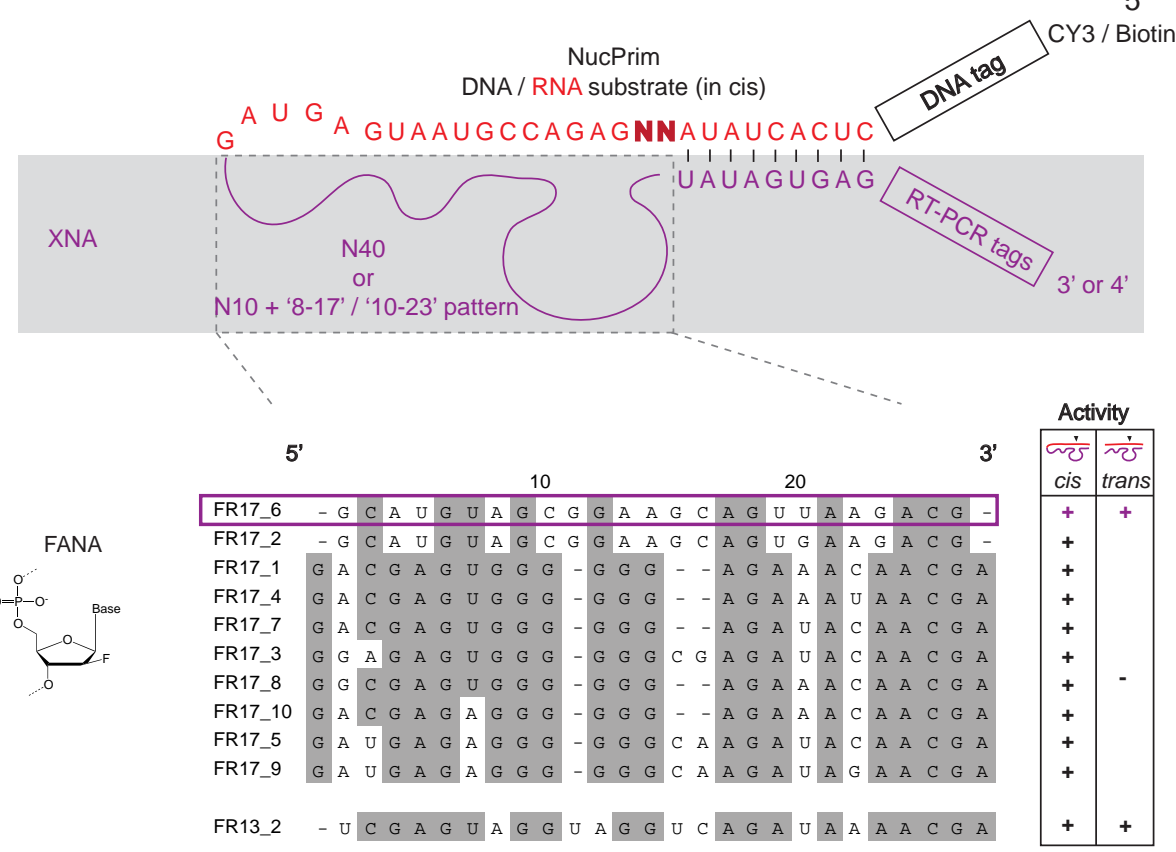

c

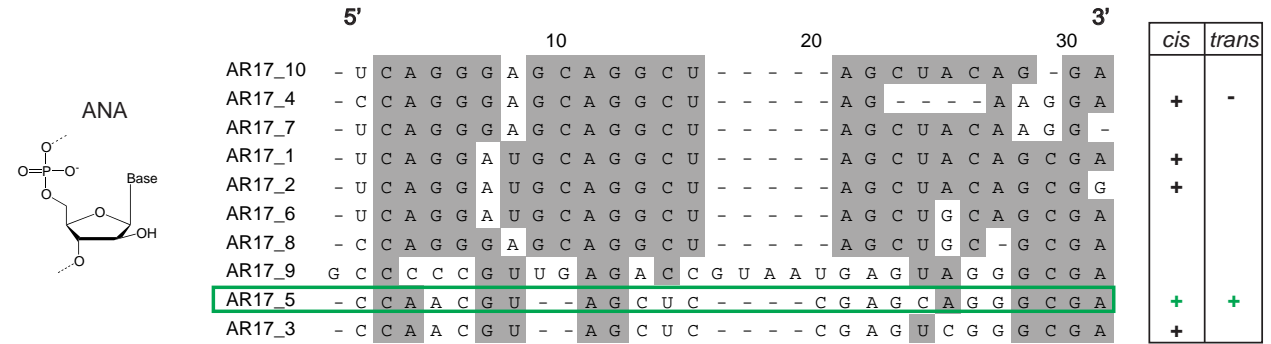

d

$6^{\prime}$

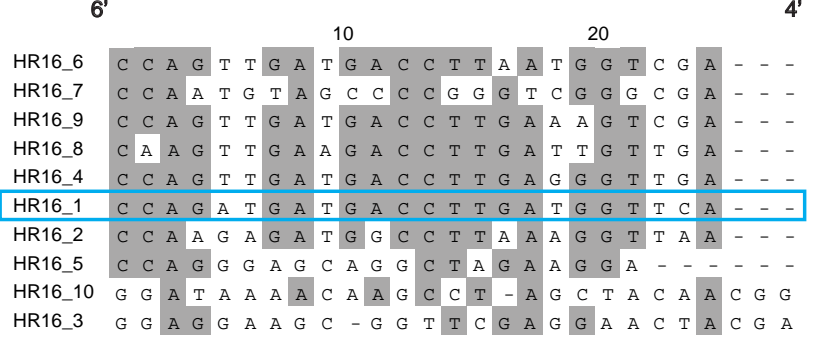

$4^{\prime}$

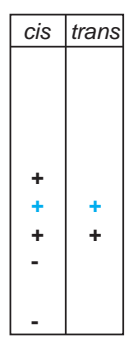

e

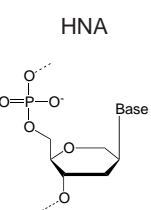

$5^{\prime}$

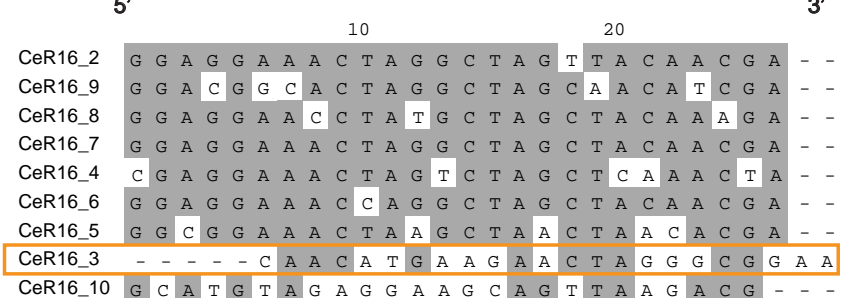

$3^{\prime}$

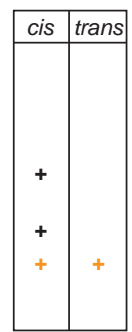

Extended Data Figure $2 \mid$ Sequences of RNA endonuclease XNAzymes. a, Schematic diagram showing DNA-RNA-(red)-XNA(purple) chimaeric library setup for selection of in cis RNA-cleaving XNAzymes. The sequences of the XNA region under selection (dashed box) of the most abundant clones revealed by deep sequencing are shown for selections using b, FANA, c, ANA, d, HNA, and e, CeNA. The top 10 sequences, or representatives of sequence families, were screened by Urea-PAGE gel shift for activity in cis (unimolecular reaction, as selected) and in trans (bimolecular reaction). Sequences chosen for further characterization are indicated by coloured boxes. 


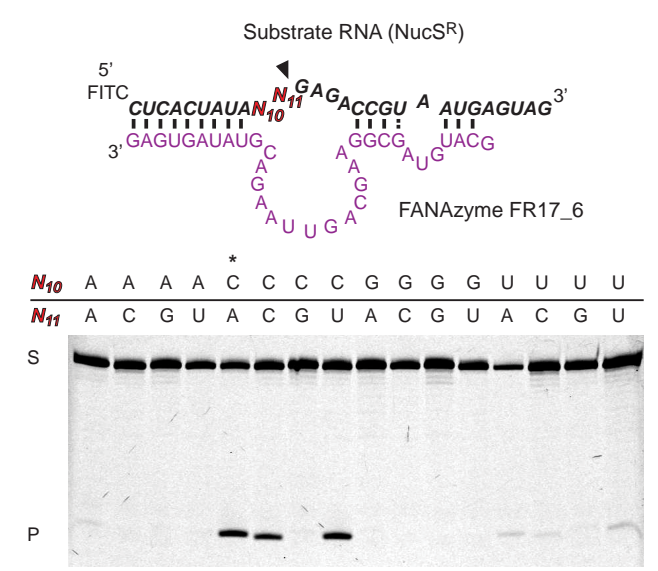

c

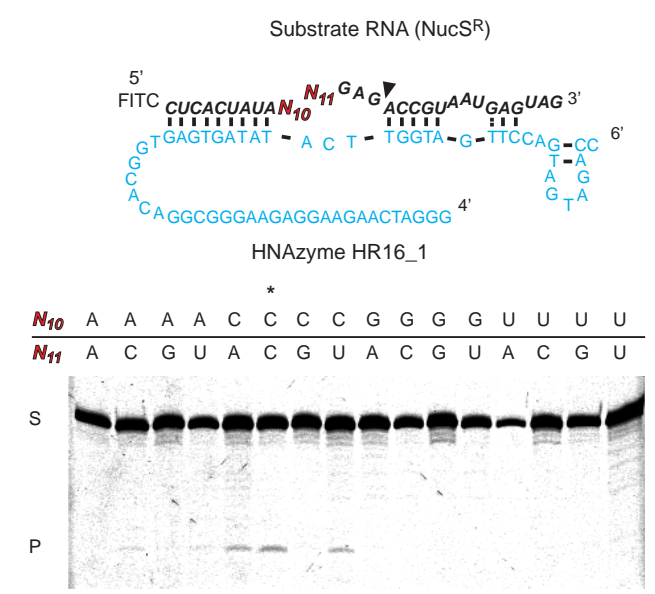

e

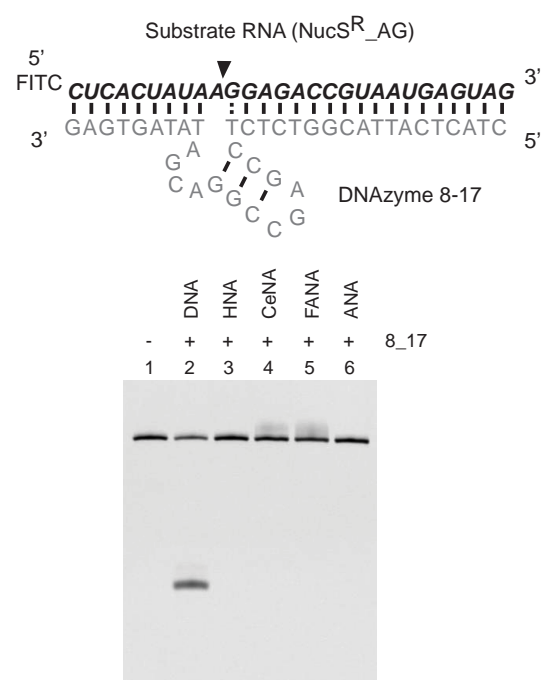

Extended Data Figure $3 \mid$ Sequence dependence of RNA endonuclease XNAzyme cleavage. XNAzymes were selected with degeneracy in the RNA substrate (see Extended Data Fig. 2a). The sequence requirements at these positions (upstream of the cleavage sites shown by a black inverted triangle) in the RNA substrate $\left(\mathrm{N}_{10}\right.$ and $\mathrm{N}_{11}$ shown in red) were determined by urea-PAGE gel shift using all 16 variants of the substrate $\mathrm{NucS}^{\mathrm{R}}$ with each XNAzyme in trans: a, FR17_6 (FANA), b, AR17_5 (ANA), c, HR16_1 (HNA), d, CeR16_3 (CeNA). e, RNA substrate $\mathrm{NucS}^{\mathrm{R}}{ }_{-}{ }_{-} \mathrm{AG}$ (lane 1) was reacted in trans with RNA b

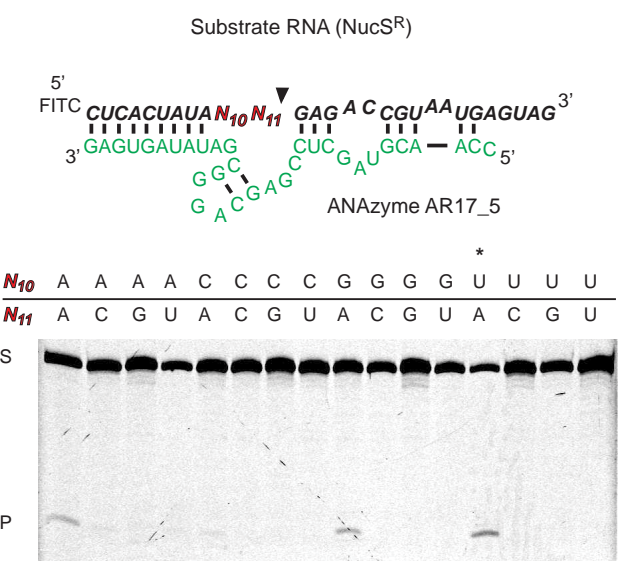

d

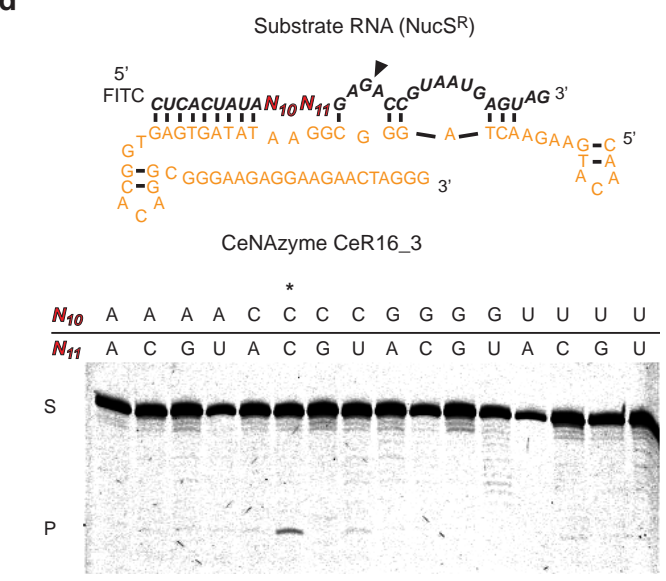

f

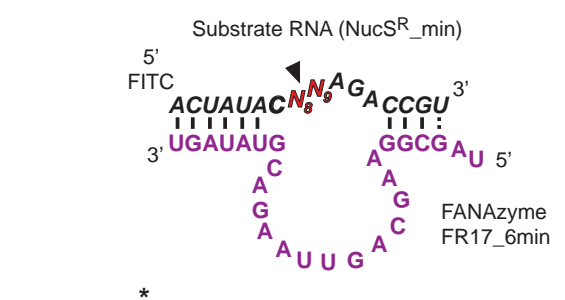

\begin{tabular}{lllllllllllllllll}
$N_{8}$ & A & A & A & A & C & C & C & C & $G$ & $G$ & $G$ & $G$ & $U$ & $U$ & $U$ & $U$ \\
\hline$N_{g}$ & A & C & G & U & A & C & G & U & A & C & G & U & A & C & G & U
\end{tabular}

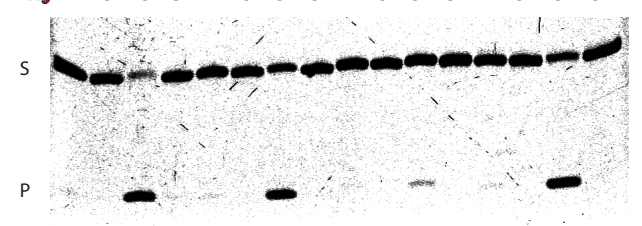

endonuclease DNAzyme 8-17 $7^{17}$ synthesized as DNA (lane 2), HNA (lane 3), CeNA (lane 4), FANA (lane 5) or ANA (lane 6). Activity of 8-17 is lost upon conversion to the XNAs described. $\mathbf{f}$, Sequence requirements for RNA cleavage by FANAzyme FR17_6 min proximal to the cleavage site (black inverted triangle), positions 8 and 9 (highlighted in red) of minimized RNA substrate NucS $^{R}$ _min. Substrate sequences used for further characterization of each XNAzyme are indicated by an asterisk. 


\section{RESEARCH LETTER}

a

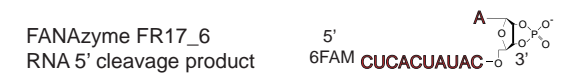

Exp. mass

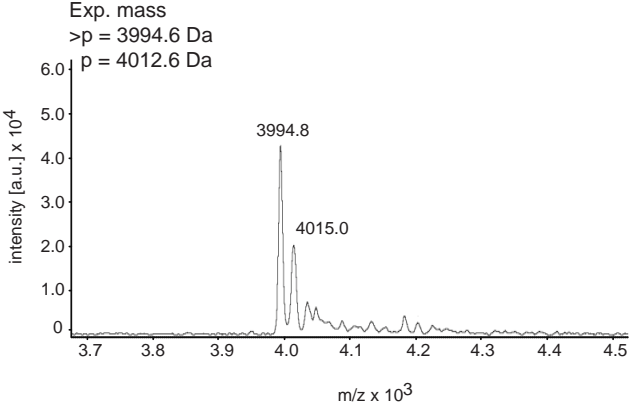

d

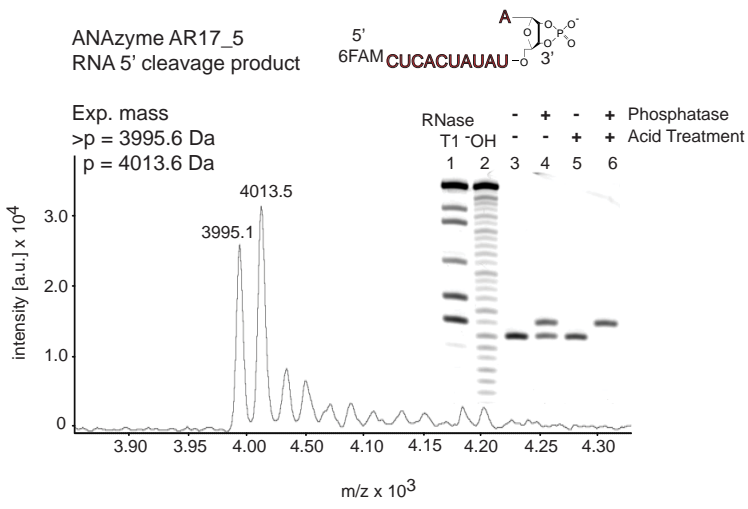

f

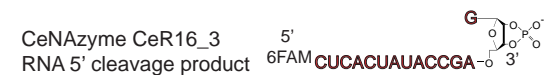

\section{Exp. mass}

$>\mathrm{p}=4990.2 \mathrm{Da}$

$\mathrm{p}=5008.2 \mathrm{Da}$

RNase - + - + Phosphatase

$\mathrm{T}^{-} \mathrm{OH}^{-}-++$Acid Treatment

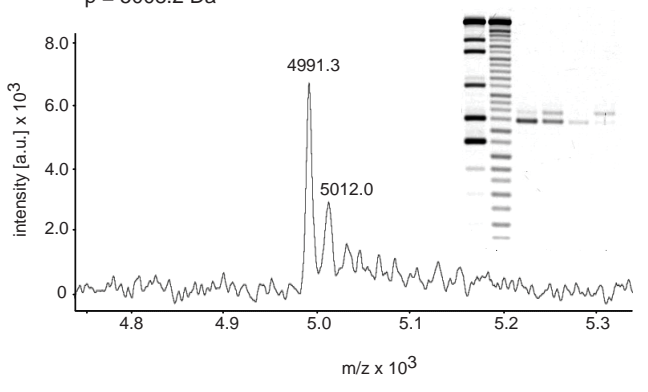

h

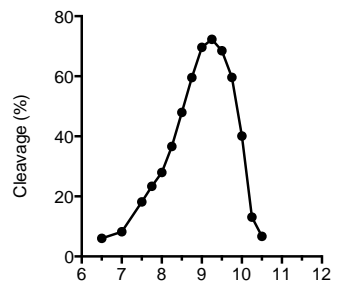

$\mathrm{pH}$

i

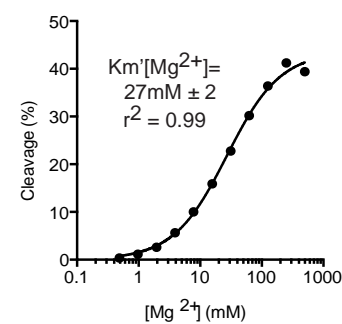

b

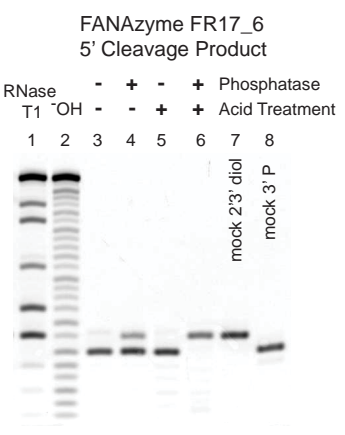

e

HNAzyme HR16 1 RNA 5' cleavage product
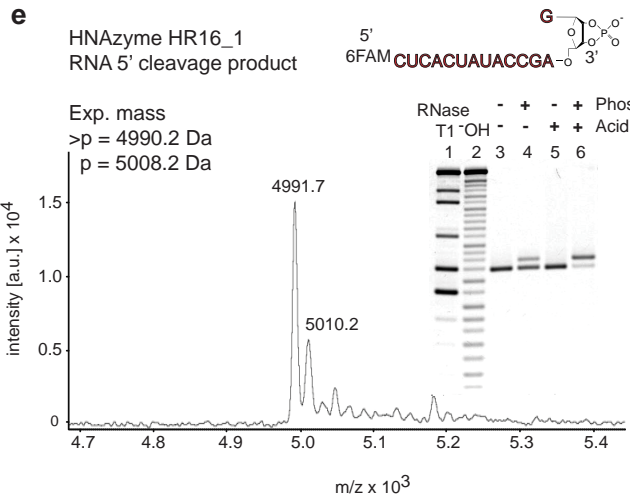

g
3' Cleavage Prodūct

${ }^{-} \mathrm{OH}^{\mathrm{RN}} \mathrm{T} 1$ - + Kinase

$\begin{array}{llll}9 & 10 & 11 & 12\end{array}$

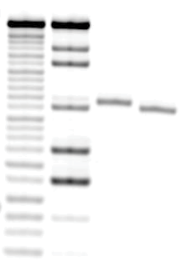


a

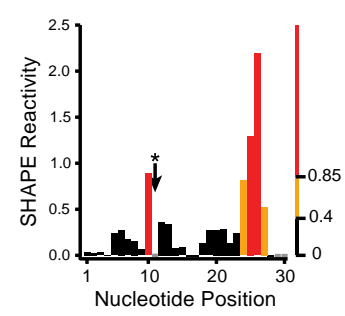

b

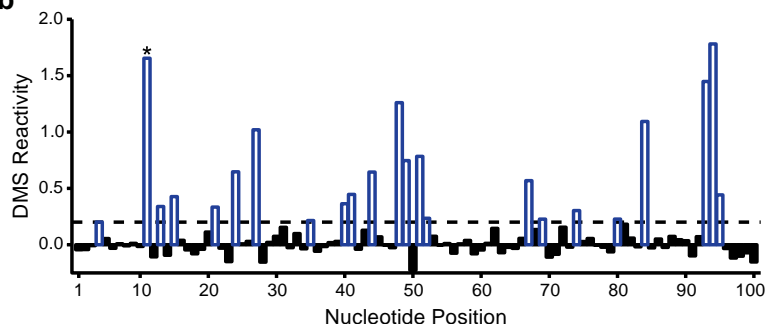

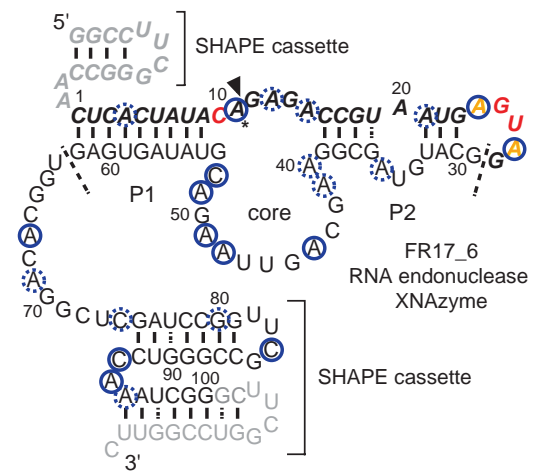

d

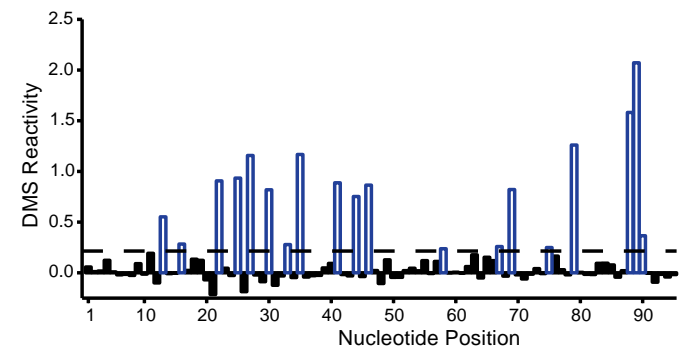

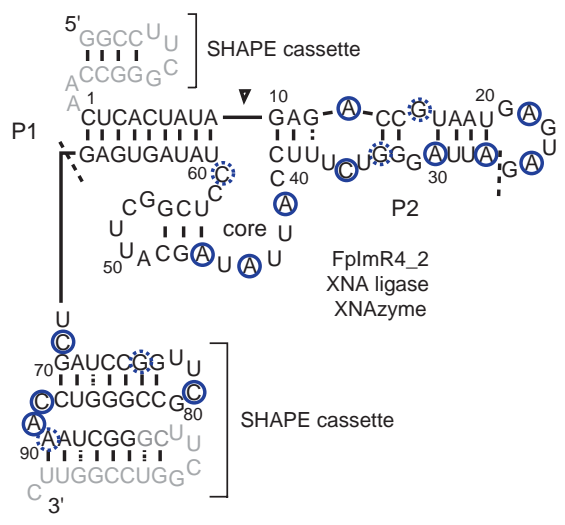

Extended Data Figure $5 \mid$ Chemical probing of XNAzyme secondary structures. a, Chemical probing using selective 2 'hydroxyl acylation analysed by primer extension (SHAPE)(RNA) ${ }^{15}$ or, b, d, dimethyl sulphate (DMS) ${ }^{16}$ (RNA and FANA) footprinting, used to inform secondary structure predictions of c, RNA endonuclease FANAzyme FR17_6 or e, FANA ligase FANAzyme FpImR4_2, embedded in structural cassettes ${ }^{15}$, with RNA substrate (inactivated by a $2^{\prime} \mathrm{O}$-methyl modification at position 11 , indicated by an asterisk in all panels) or FANA product in cis. SHAPE analyses RNA 2'OH. Black, orange and red solid bars and bases indicate low, moderate, and high SHAPE reactivity, respectively, for positions 1-28 in FR17_6 construct, corresponding to RNA substrate $\mathrm{NucS}^{\mathrm{R}}$. DMS reacts predominantly with A and C bases (RNA and FANA). Positions were defined as reactive (blue open bars and circles) if reactivity was greater than a cut-off (dashed line in $\mathbf{b}$ and $\mathbf{d}$ ) of one half standard deviation above the median. Dashed circles indicate positions with marginal reactivity. Site of cleavage (in unmodified RNA) or ligation is indicated by a black inverted triangle. Primer-binding regions (no structural data) are shown in grey. 


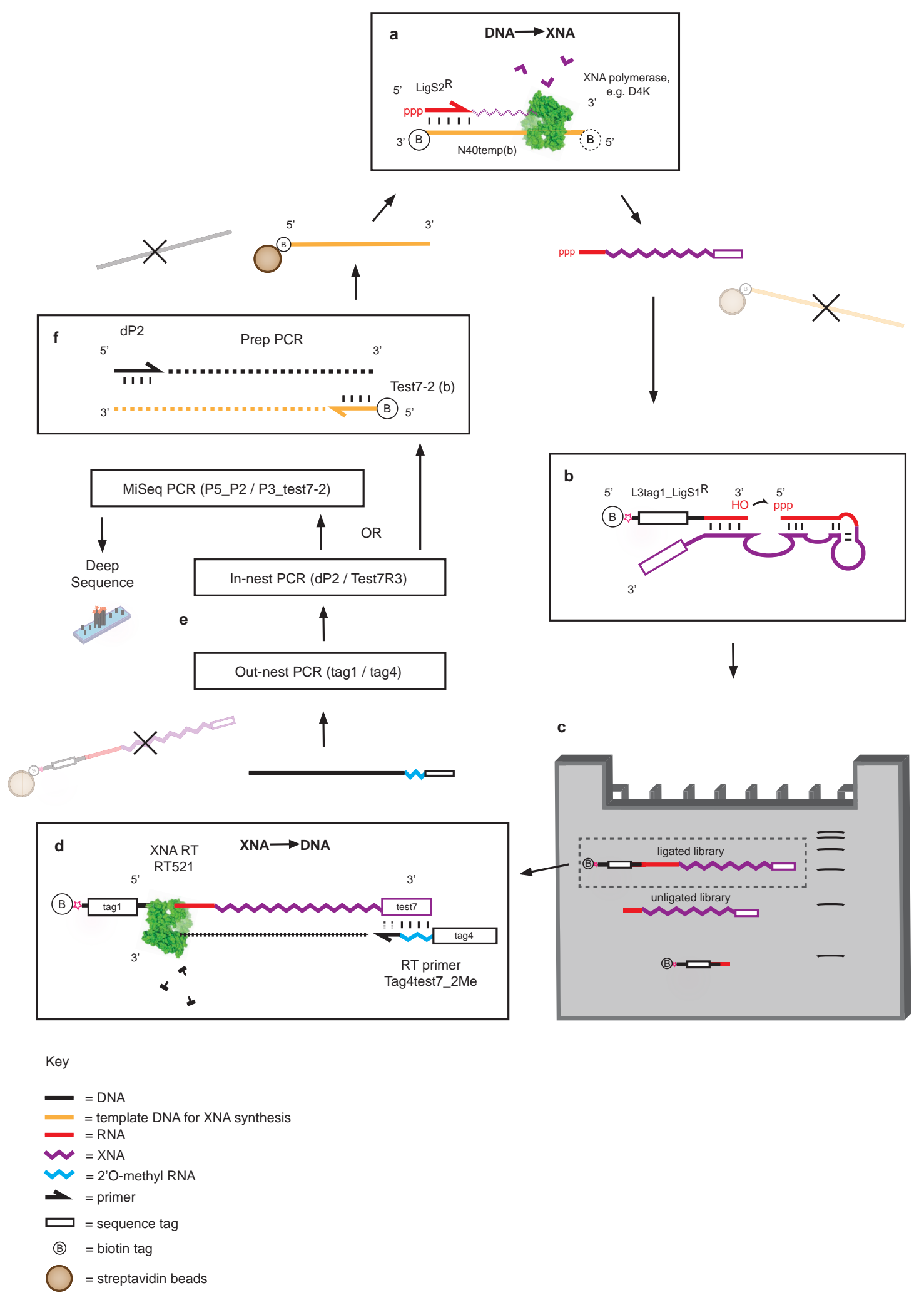

Extended Data Figure 6 | Selection scheme for RNA ligase XNAzymes. a, XNA library preparation using DNA-dependent XNA polymerases, primed by a $5^{\prime}$ triphosphorylated (5' ppp) RNA primer $\left(\operatorname{LigS2}{ }^{\mathrm{R}}\right)$, which serves as one of the substrates for RNA ligation in cis. Libraries are synthesized with 3' biotinylated DNA templates (N40temp(b); see Supplementary Table 1), allowing subsequent capture and removal by streptavidin beads. b, Singlestranded libraries (unbiotinylated) are annealed and incubated in reaction buffer (see Methods) together with a biotinylated chimaeric DNA-RNA substrate (tag1_LigS1 ${ }^{\mathrm{R}}$ ), which successful XNAzymes ligate to RNA substrate LigS2 ${ }^{\mathrm{R}}$ in cis. c, Size separation of reacted XNA pools using urea-PAGE. Ligated
XNA pools are gel-extracted (indicated by dashed box). d, Reverse transcription of XNA pools using XNA-dependent DNA polymerase RT521L, which is also able to transcribe RNA across the ligation junction (that is, [RNA-RNA-XNA] $\rightarrow$ cDNA). e, Amplification of transcribed cDNA by successive PCR reactions, using the primers indicated (see Supplementary Table 1); out-nest reaction depends on priming site (tag1) from ligated substrate tag1_LigS1 ${ }^{\mathrm{R}}$.f, PCR reaction generating templates for XNA synthesis (now $5^{\prime}$ biotinylated) for further rounds of selection. Solid crosses indicate removal of denatured strands using streptavidin bead capture. 


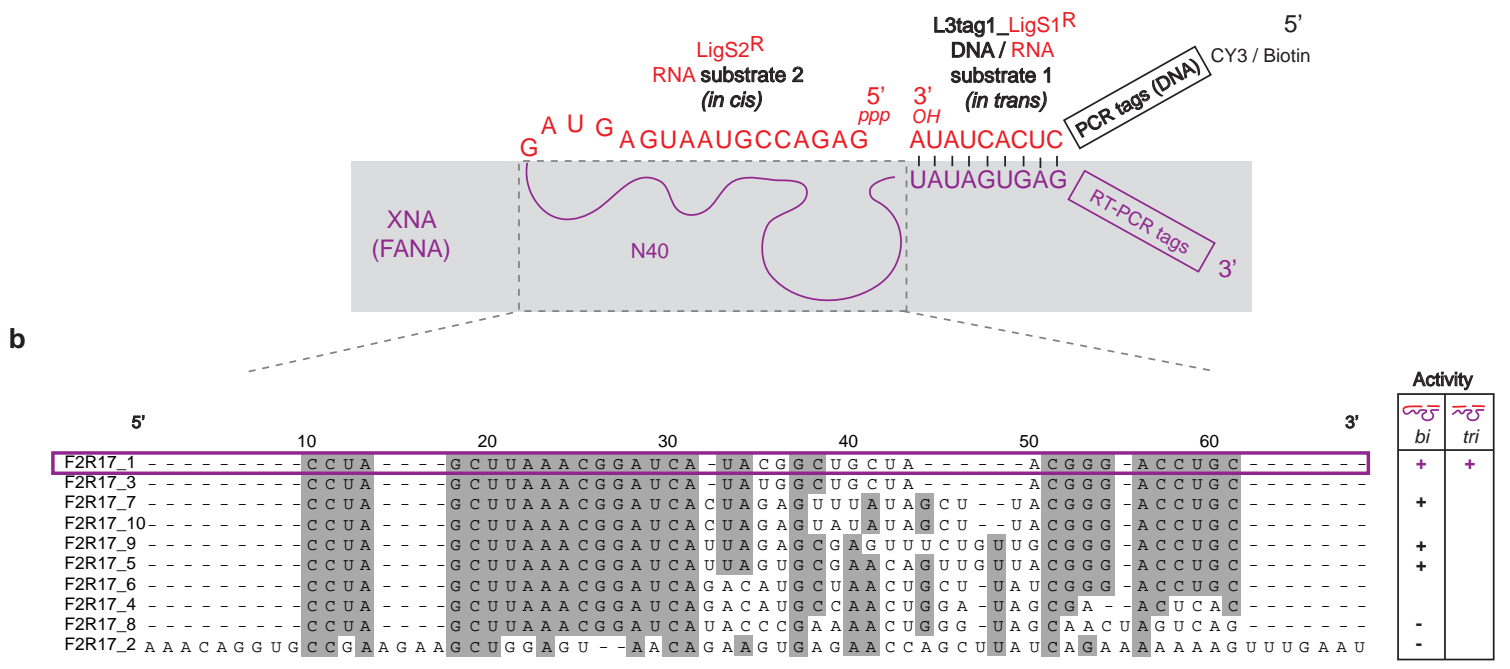

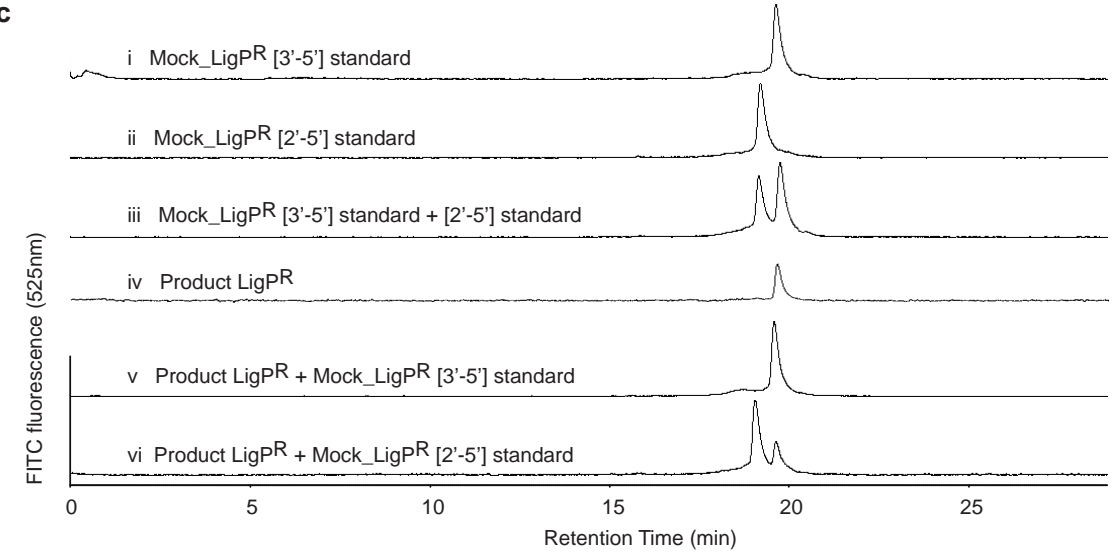

\begin{tabular}{cc}
\hline Metal additive & Activity \\
\hline- & - \\
$4 \mathrm{M} \mathrm{K}^{+}$ & - \\
{$\left[\mathrm{Co}\left(\mathrm{NH}_{3}\right)_{6}\right]^{3+}$} & - \\
$\mathrm{Mg}^{2+}$ & +++ \\
$\mathrm{Ca}^{2+}$ & - \\
$\mathrm{Mn}^{2+}$ & +++ \\
$\mathrm{Fe}^{2+}$ & - \\
$\mathrm{Co}^{2+}$ & - \\
$\mathrm{Ni}^{2+}$ & - \\
$\mathrm{Cu}^{2+}$ & - \\
$\mathrm{Zn}^{2+}$ & - \\
$\mathrm{Sr}^{2+}$ & - \\
$\mathrm{Cd}^{2+}$ & - \\
$\mathrm{Ba}^{2+}$ & - \\
\hline
\end{tabular}

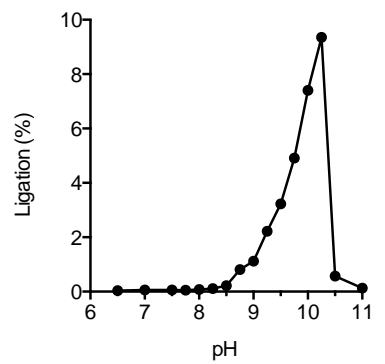

f

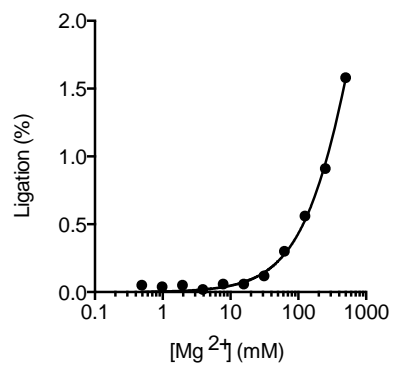

g

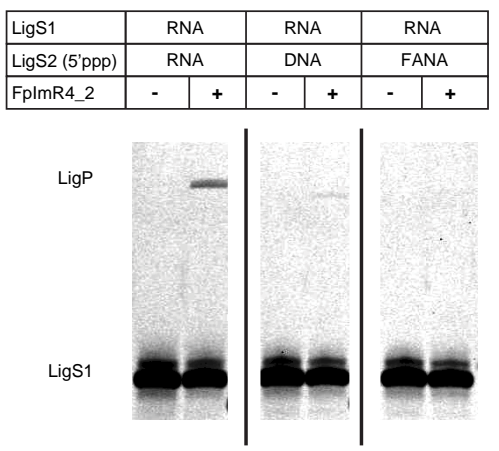

Extended Data Figure $7 \mid$ Sequences and analyses of RNA ligase XNAzymes. a, Schematic diagram showing RNA (red)-XNA (purple) chimaeric library setup for selection of FANAzymes capable of catalysing a bimolecular RNA ligation. $\mathbf{b}$, Sequences of the FANA region under selection (dashed box in $\mathbf{a}$ ) of the most abundant clones revealed by deep sequencing. Representatives of sequence families were screened for activity in bimolecular $\left(\operatorname{LigS} 2^{\mathrm{R}}\right.$ attached to XNAzyme) or trimolecular (XNAzyme separate from both substrates) reactions. Sequence F2R17_1 (boxed) was chosen for further characterization. c, Regiospecificity of RNA product $\left(\operatorname{LigP}^{\mathrm{R}}\right)$ of ligation catalysed by XNAzyme F2R17_1min (see Fig. 3), analysed by strong anion exchange chromatography $(\text { SAX-HPLC) })^{36}$. Mock RNA ligation product (i-iii) containing a single $2^{\prime}-5^{\prime}$ $\left(\right.$ Mock_LigP $\left.{ }^{\mathrm{R}}\left[2^{\prime}-5^{\prime}\right]\right)$ or $3^{\prime}-5^{\prime}$ linkage $\left(\right.$ Mock_LigP $\left.\mathrm{R}^{\mathrm{R}}\left[3^{\prime}-5^{\prime}\right]\right)$ at a position analogous to the ligation site were compared to the XNAzyme-catalysed RNA product LigP $\mathrm{P}^{\mathrm{R}}$ (iv-vi). The XNAzyme product gives an identical elution profile to the natural $\left(3^{\prime}-5^{\prime}\right)$ linkage standard. d, Bivalent metal ion requirements and titration of, $\mathbf{e}, \mathrm{pH}$ or $\mathbf{f}, \mathrm{MgCl}_{2}$, of FANAzyme F2R17_1min reaction. g, Substitution of RNA ligase substrates with DNA and XNA (FANA) versions in F2R17_1min reaction shows that $5^{\prime}$-RNA-RNA-3' ligation is preferred, but some ligase activity can be seen with $5^{\prime}$-RNA-DNA-3'. 

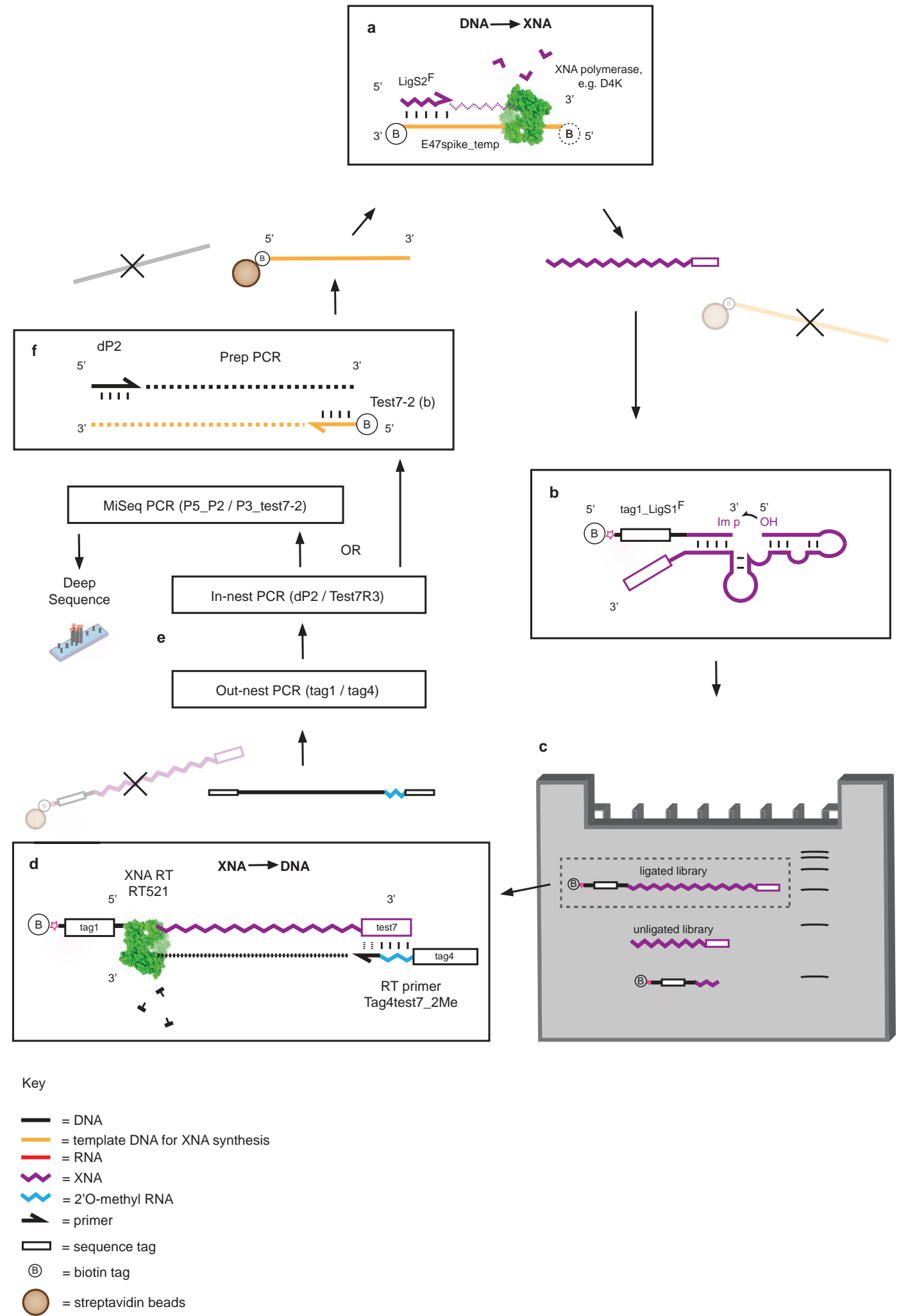

Extended Data Figure 8 | Selection scheme for XNA ligase XNAzymes. a, XNA library preparation using DNA-dependent XNA polymerases, primed by an all-XNA (FANA) primer $\left(\operatorname{LigS}^{\mathrm{F}}\right)$, which serves as one of the substrates for FANA ligation in cis. Libraries are synthesized with 3' biotinylated DNA template (E47spike_temp; see Supplementary Table 1), allowing subsequent capture and removal by streptavidin beads. b. Single-stranded libraries (unbiotinylated) are annealed and incubated in reaction buffer (see Methods) together with a biotinylated chimaeric DNA-XNA (FANA) substrate $\left(\operatorname{tag} 1 \_L i g S 1^{\mathrm{F}}\right)$, activated with a $3^{\prime}$ phosphorylimidazolide (Extended Data Fig. 10), which successful XNAzymes ligate to XNA (FANA) substrate $\operatorname{LigS2}^{\mathrm{F}}$ in cis. c, Size separation of reacted XNA pools using urea-PAGE. Ligated XNA pools are gel-extracted (indicated by dashed box). d, Reverse transcription of XNA pools using XNA-dependent DNA polymerase RT521L (that is, XNA $\rightarrow$ cDNA). e, Amplification of transcribed cDNA by successive PCR reactions, using the primers indicated (see Supplementary Table 1); out-nest reaction depends on priming site (tag1) from ligated substrate tag1_LigS1 ${ }^{\mathrm{F}}$. f, PCR reaction generating templates for XNA synthesis (now $5^{\prime}$ biotinylated) for further rounds of selection. Solid crosses indicate removal of denatured strands using streptavidin bead capture. 

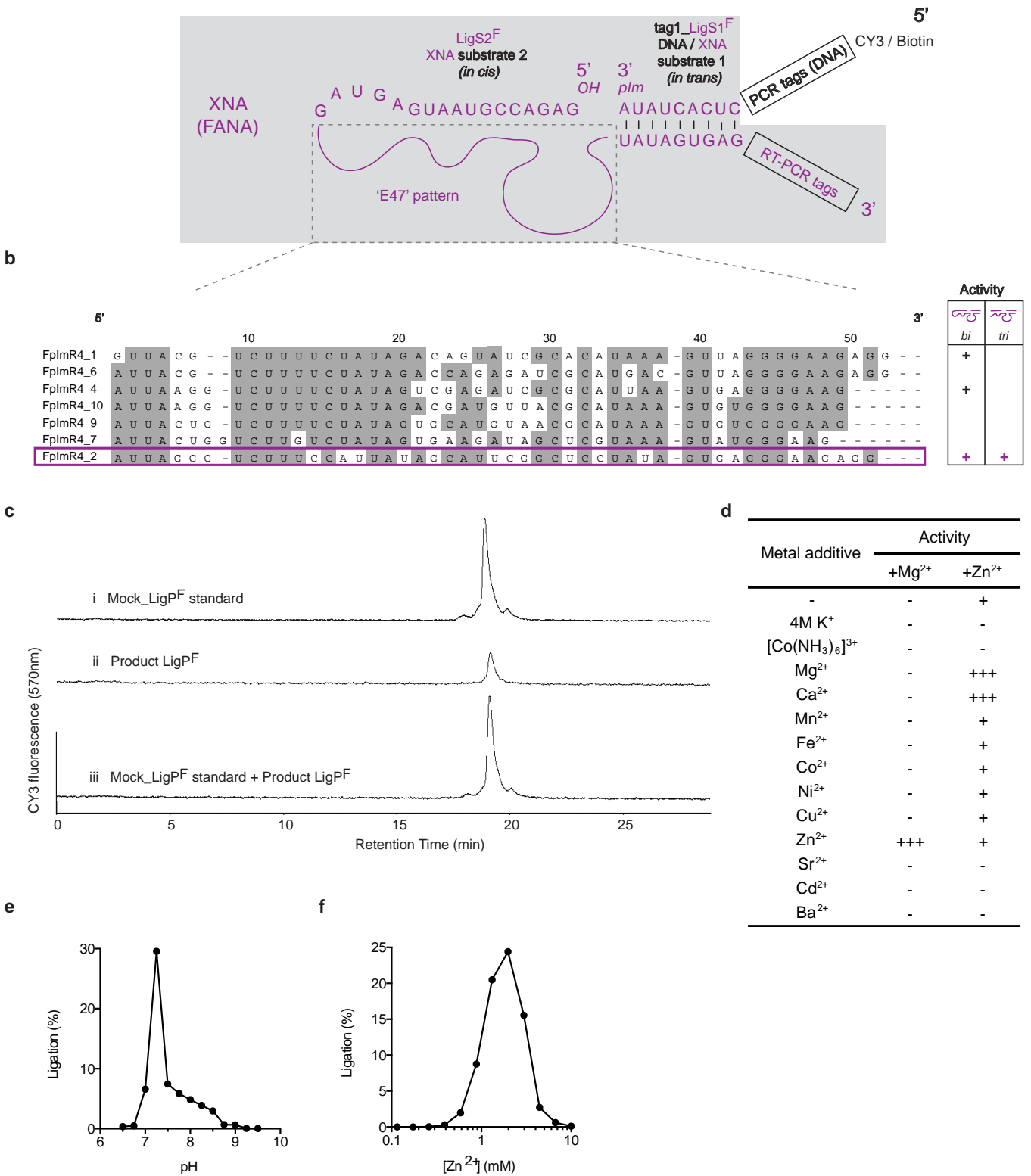

g

\begin{tabular}{|c|c|c|c|c|c|c|c|}
\hline LigS1 (3' plm) & FANA & & & & & & \\
\hline LigS2 & FANA & & & & & & \\
\hline FplmR4_2 & - & - & + & - & + & - & + \\
\hline
\end{tabular}

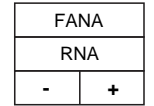

LigP
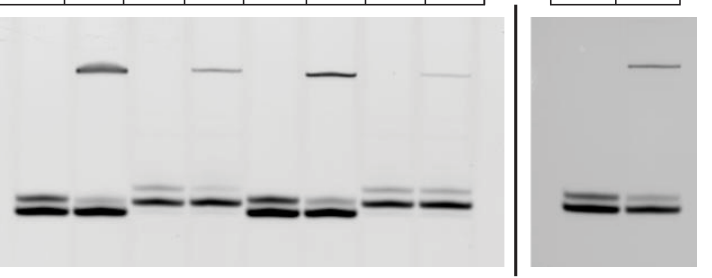

Extended Data Figure 9 | Sequences and analyses of XNA ligase XNAzymes (FANA). a, Schematic diagram showing all-FANA library setup for selection of FANAzymes capable of catalysing a bimolecular XNA (FANA) ligation. b. FANA sequences of the region under selection (dashed box in a) of the most abundant clones revealed by deep sequencing. Representatives of sequence families were screened for activity in bimolecular (LigS2 ${ }^{\mathrm{F}}$ attached to XNAzyme) or trimolecular (XNAzyme separate from both substrates) reactions. Sequence FpImR4_2 (boxed) was chosen for further characterization. c, Regiospecificity of XNA (FANA) product $\left(\operatorname{LigP}^{\mathrm{F}}\right)$ of ligation catalysed by XNAzyme FpImR4_2 (see Fig. 4), analysed by strong anion exchange chromatography (SAX-HPLC). Mock FANA ligation product $\left(\right.$ Mock_LigP ${ }^{\mathrm{F}}$ ) (i), prepared by polymerase (D4K) gives an identical elution profile to the XNAzyme-catalysed FANA product $\left(\mathrm{LigP}^{\mathrm{F}}\right)$ (ii and iii). d, Bivalent metal ion requirements and titration of, $\mathbf{e}, \mathrm{pH}$ or $\mathbf{f}, \mathrm{MgCl}_{2}$, of FANAzyme FpImR4_2 reaction. g, Substitution of XNA ligase substrates with RNA and DNA versions in FpImR4_2 reaction. Although 5'-FANA-FANA-3' is preferred, ligase activity can be seen with $5^{\prime}$-FANA-DNA- ${ }^{\prime}$, and $5^{\prime}$-FANA-RNA-3' ${ }^{\prime}$, as well as $5^{\prime}$-DNA-FANA- ${ }^{\prime}, 5^{\prime}$-DNA-DNA-3' ${ }^{\prime}$ and 5'-DNA-RNA-3'. 


\section{RESEARCH LETTER}

a

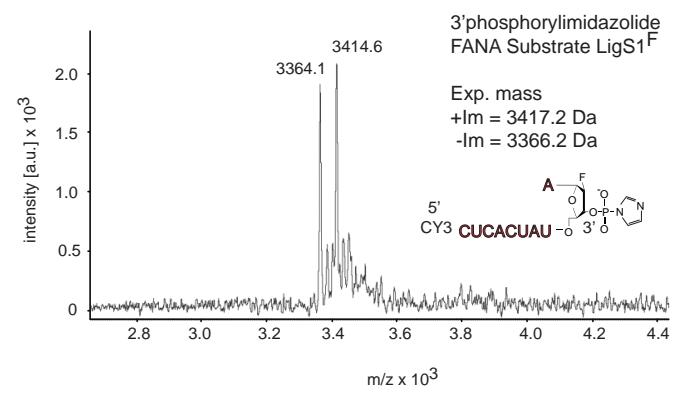

C

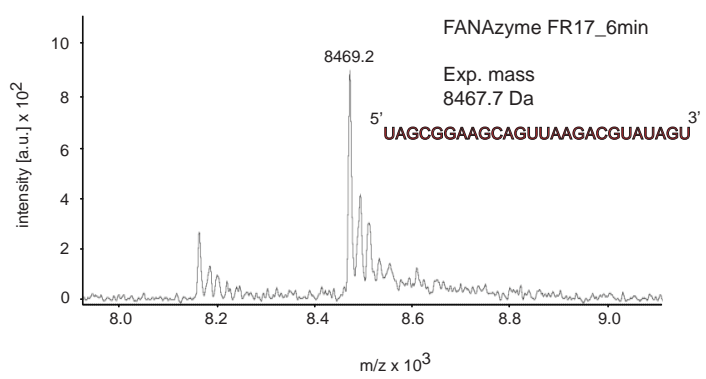

e

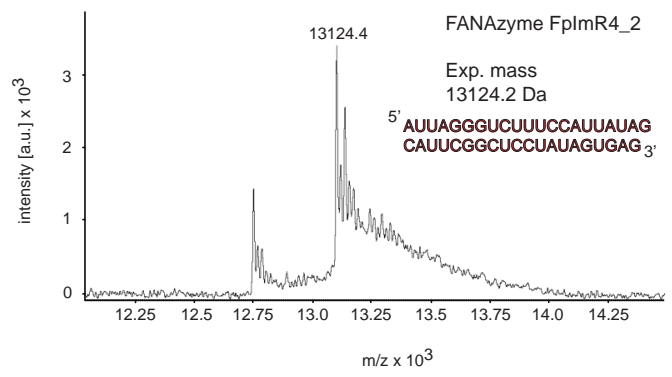

g

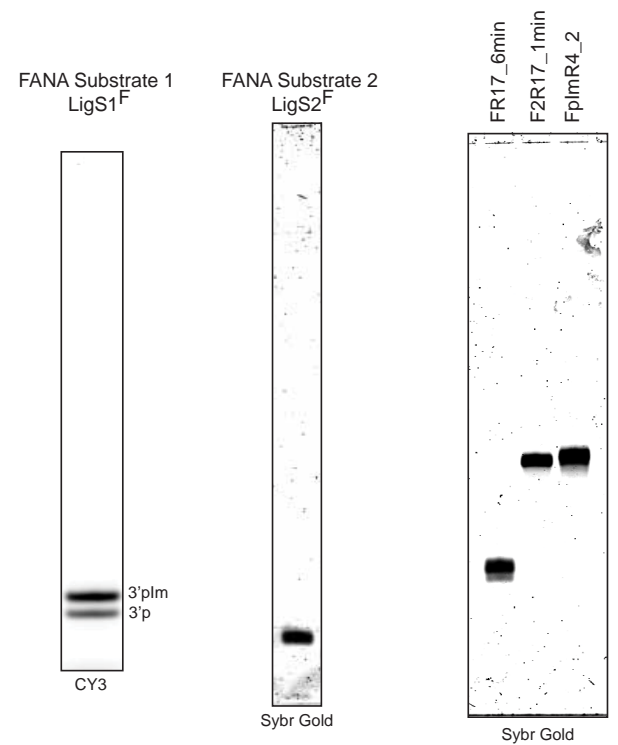

Extended Data Figure $10 \mid$ Analysis of XNA (FANA) substrates and enzymes prepared by solid-phase synthesis. MALDI-ToF mass spectra showing expected masses of a, XNA (FANA) ligase substrate $\mathrm{LigSi}^{\mathrm{F}}$ 3' phosphorylimidazolide (prepared by solid-phase synthesis of the $3^{\prime}$ phosphorylated ( $3^{\prime} \mathrm{p}$ ) oligonucleotide, followed by reaction with carbodiimide and imidazole (see Methods)), b, XNA (FANA) ligase substrate LigS2 ${ }^{\mathrm{F}}$, and XNAzymes c, FR17_6min, d, F2R17_6min, and e, FpImR4_2. b

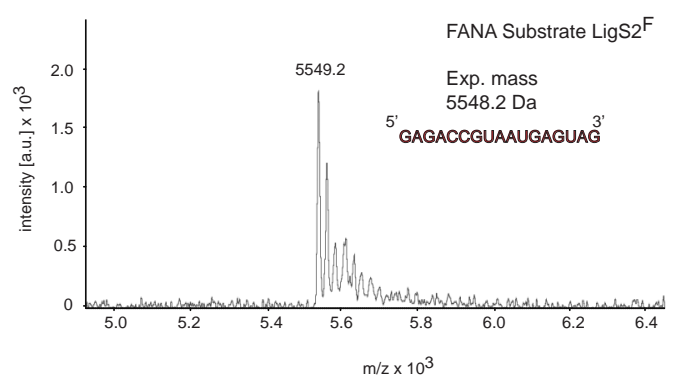

d

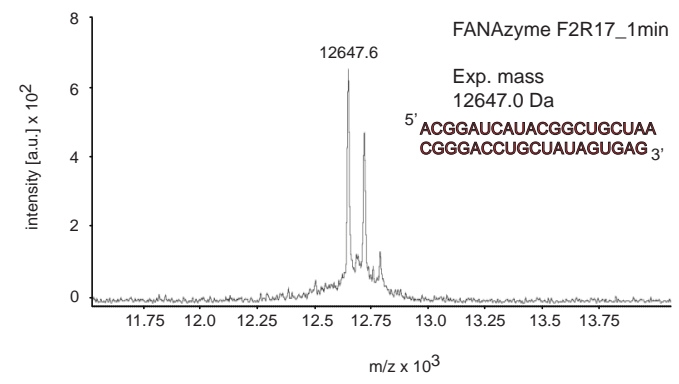

$\mathbf{f}$
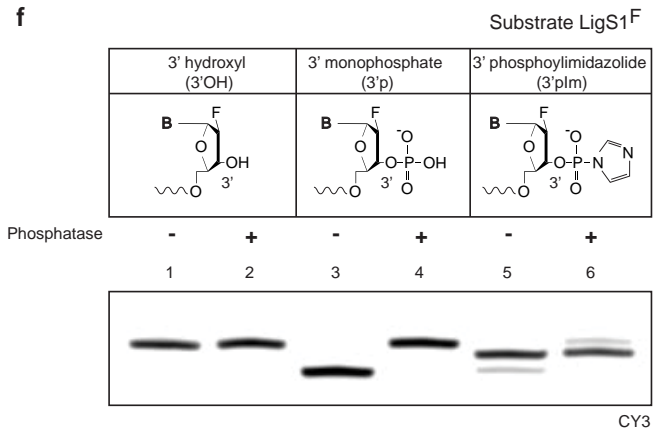

f, Dephosphorylation assay of versions of $\operatorname{LigS1}^{\mathrm{F}}$ ( $3^{\prime}$ hydroxyl, lanes 1 and 2, $3^{\prime}$ phosphate, lanes 2 and 3, or $3^{\prime}$ phorphorylimidazolide, lanes 5 and 6) with calf intestinal phosphatase (lanes 2, 4 and 6). The majority of the $\operatorname{LigS1}^{\mathrm{F}}$ preparation shown $(\sim 70 \%)$ is protected from dephosphorylation, consistent with formation of the $3^{\prime} \mathrm{pIm}$. g, Urea-PAGE analyses of purified FANA substrates and XNAzymes. 